Aus dem Institut für Neuropathologie

(Prof. Dr. med. C. Stadelmann-Nessler)

der Medizinischen Fakultät der Universität Göttingen

\title{
Prävalenz, Antibiotikaresistenz und klinische Relevanz einer Besiedlung des Respirationstraktes mit Streptococcus pneumoniae in einer geriatrischen Klinik
}

\author{
INAUGURAL-DISSERTATION \\ zur Erlangung des Doktorgrades \\ der Medizinischen Fakultät der \\ Georg-August-Universität zu Göttingen
}

vorgelegt von

Nina Isabel Jomrich

aus

Stuttgart

Göttingen 2019 
Dekan:

Betreuungsausschuss

Betreuer:

Ko-Betreuer:

\section{Prüfungskommission}

Referent:

Ko-Referent:

Datum der mündlichen Prüfung: 25.11.2020
Prof. Dr. med. R. Nau

Prof. Dr. med. Dr. rer. nat. H. Eiffert

Prof. Dr. med. Dr. rer. nat. H. Eiffert 
Hiermit erkläre ich, die Dissertation mit dem Titel "Prävalenz, Antibiotikaresistenz und klinische Relevanz einer Besiedlung des Respirationstraktes mit Streptococcus pneumoniae in einer geriatrischen Klinik" eigenständig angefertigt und keine anderen als die von mir angegebenen Quellen und Hilfsmittel verwendet zu haben.

Göttingen, den

(Unterschrift) 
Die Daten, auf denen die Arbeit basiert, wurden teilweise publiziert:

Jomrich N, Kellner S, Djukic M, Eiffert H, Nau R (2015): Absence of Streptococcus pneumoniae in pharyngeal swabs of geriatric inpatients. Infect Dis (Lond) 47, 504-509 


\section{Inhaltsverzeichnis}

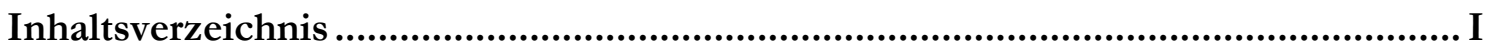

Abbildungsverzeichnis ....................................................................................... III

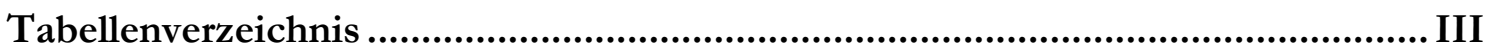

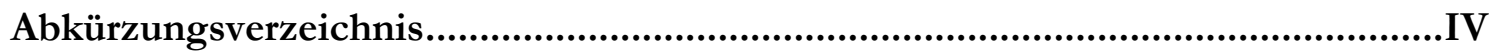

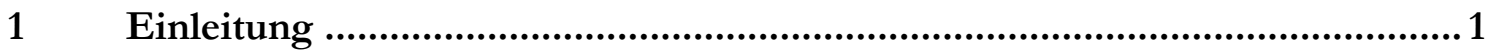

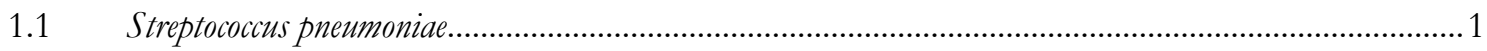

1.2 Morphologie und laborchemische Eigenschaften....................................................................

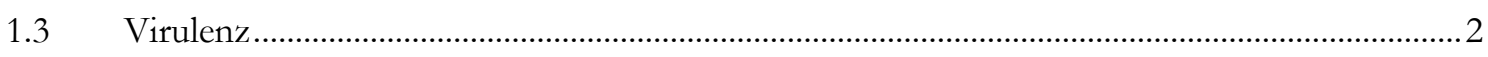

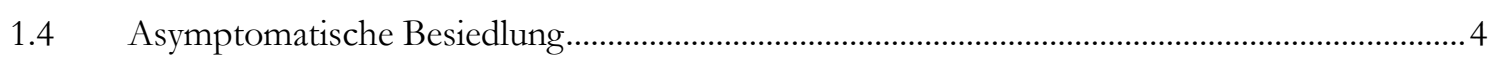

1.5 Erkrankungen durch S. pneumoniae ...................................................................................

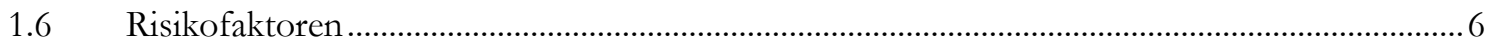

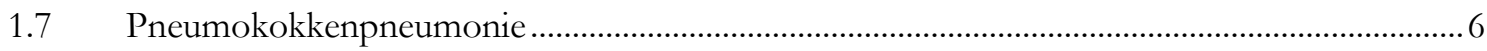

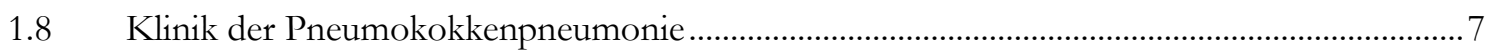

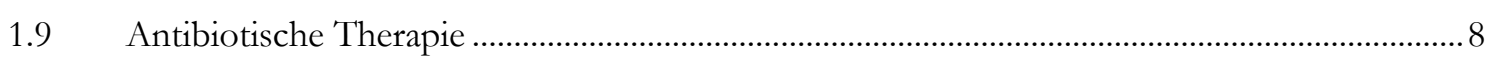

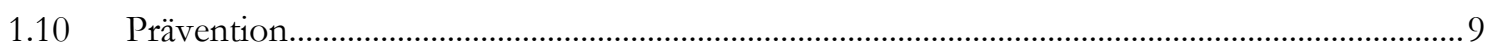

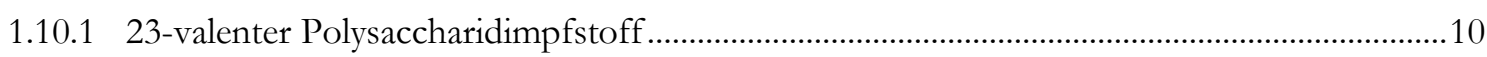

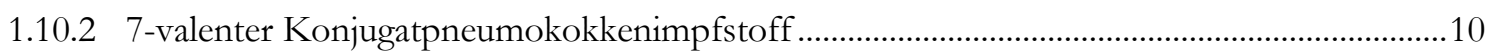

1.10 .3 13-valenter Konjugatpneumokokkenimpfstoff........................................................................

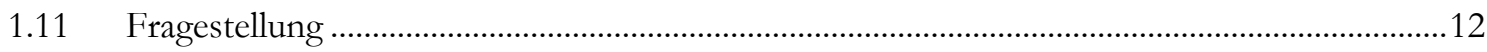

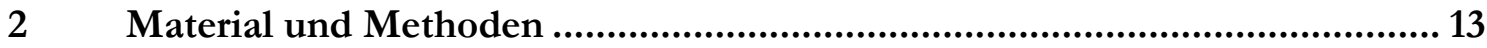

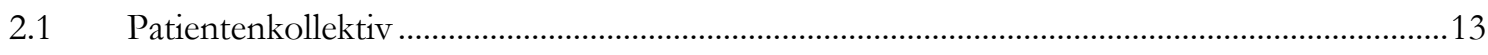

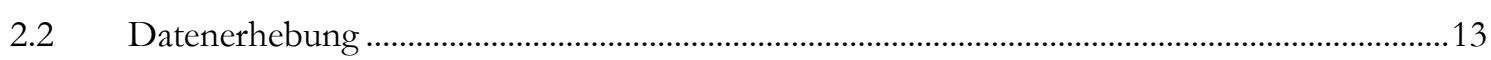

2.3 Ausfüllen der Fragenbögen...............................................................................................

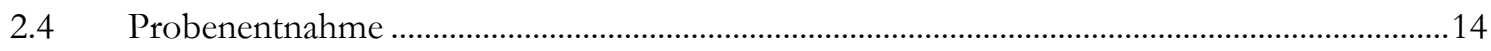

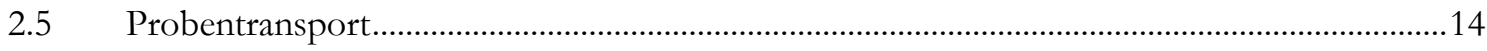

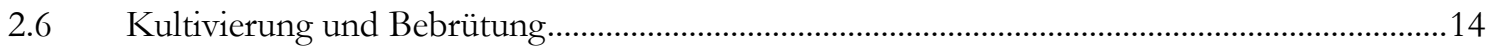

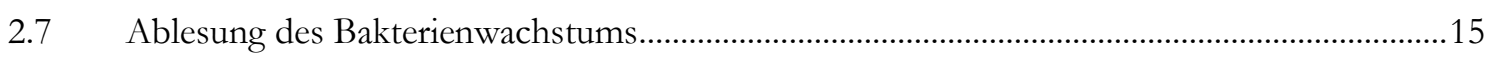

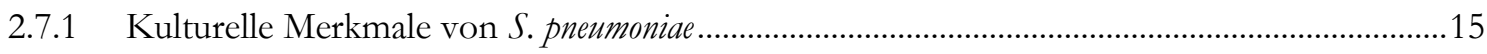

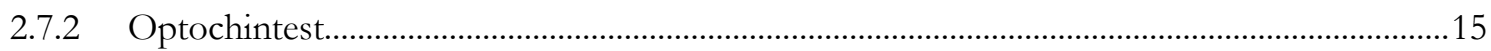

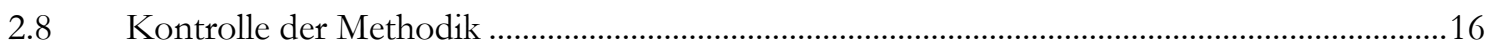

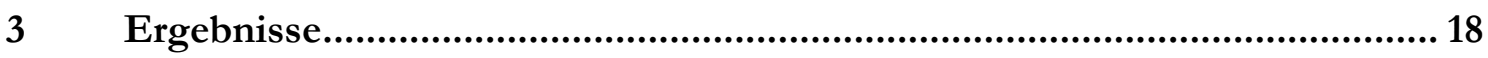

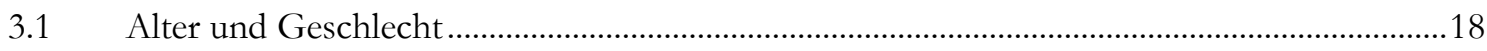

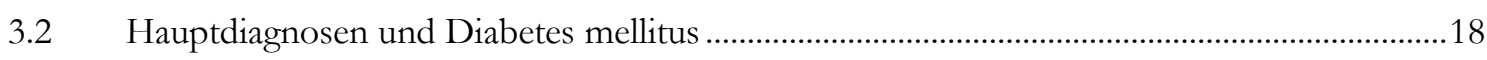




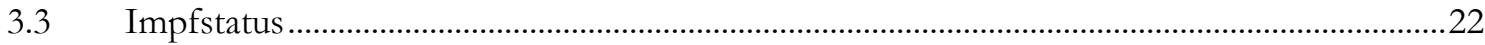

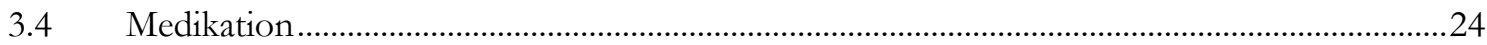

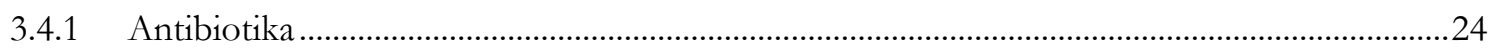

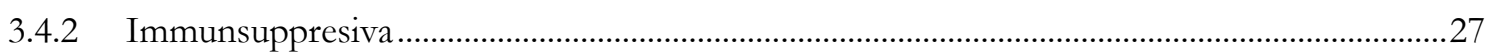

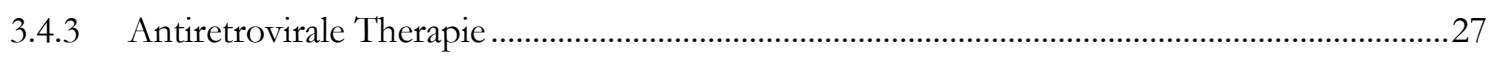

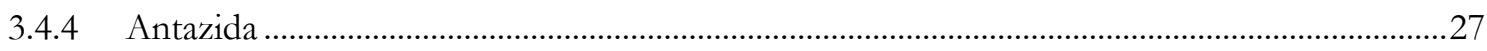

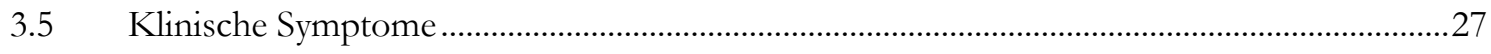

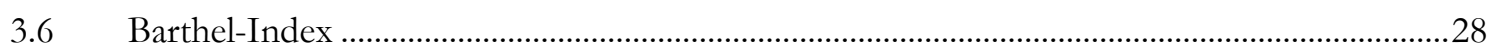

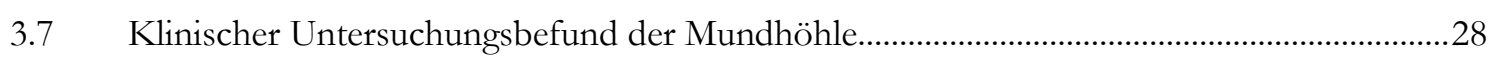

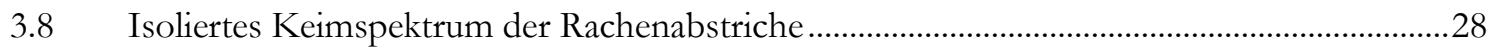

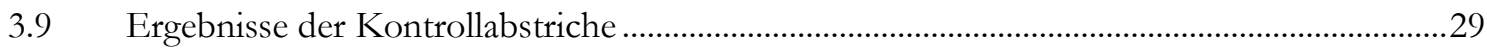

$4 \quad$ Diskussion............................................................................................. 30

4.1 Besiedlung des Respirationstraktes durch S. pneumoniae bei alten Menschen ........................30

4.2 Saisonale Unterschiede der Besiedlungsraten ..........................................................................31

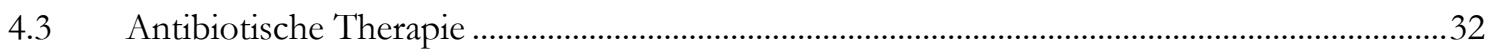

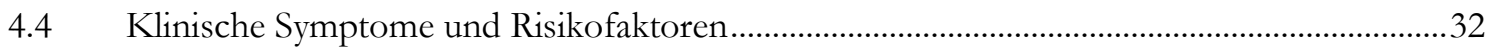

4.5 Oropharyngeale Probenentnahme und Methodik ..............................................................32

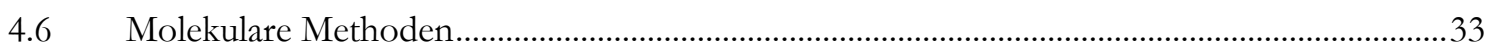

4.7 Ambulant erworbene Pneumonie durch S. pneumoniae ................................................................33

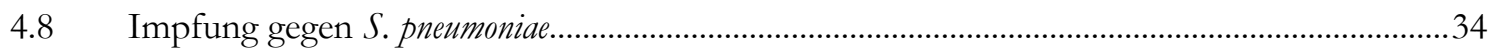

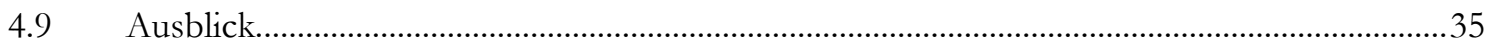

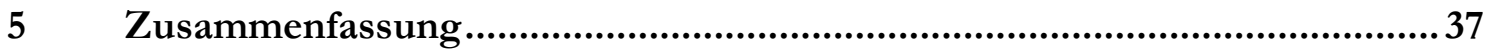

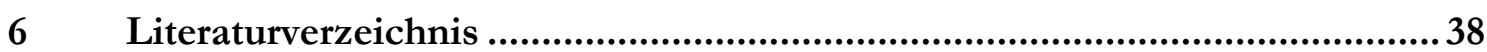

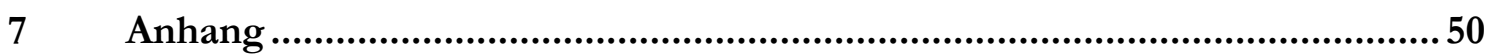




\section{Abbildungsverzeichnis}

Abbildung 1: Hauptdiagnosen

Abbildung 2: Hauptdiagnosen: Internistische Erkrankungen .............................................................20

Abbildung 3: Hauptdiagnosen: Orthopädische/unfallchirurgische Erkrankungen...............................20

Abbildung 4: Nebendiagnosen: Risikofaktor Diabetes mellitus .........................................................21

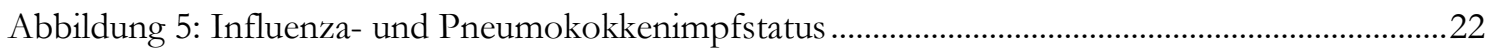

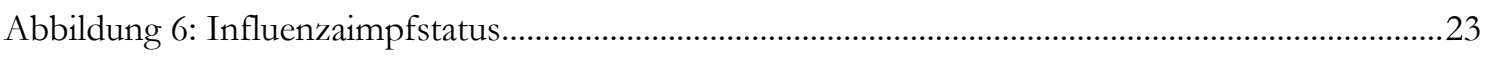

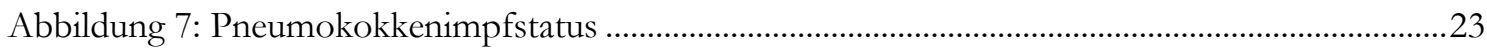

Abbildung 8: Antibiotikabehandlung vor und während der Probenentnahme ......................................26

Abbildung 9: Eingenommene antibiotische Substanzgruppen ............................................................26

Abbildung 10: Auf den Respirationstrakt bezogene klinische Symptome während der

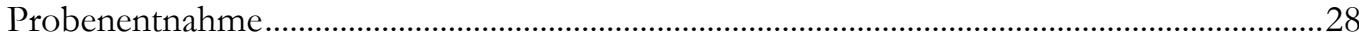

Abbildung 11: Nachgewiesene potentiell pathogene Keime ..............................................................29

\section{Tabellenverzeichnis}

abelle 1: Auflistung der eingenommenen antibiotischen Wirkstoffe vor und während der Probenentnahme 


\section{Abkürzungsverzeichnis}

BSG Blutsenkungsgeschwindigkeit

CAP community-aquired pneumonia

CAPITA Community-Acquired Pneumonia Immunization Trial in Adults

COPD chronic obstructive pulmonary disease

CRP C-reaktives Protein

ESBL Extended Spectrum Beta-Laktamase

HIV buman immunodeficiency virus

IPD invasive pneumococcal disease

P. Pseudomonas

PPSV pneumococcal polysaccharide vaccine

PCV pneumococcal conjugate vaccine

PspA Pneumokokkenoberflächenprotein A

PspC Pneumokokkenoberflächenprotein C

S. Streptococcus

STIKO Ständige Impfkommission 


\subsection{Streptococcus pneumoniae}

S. pneumoniae ist einer der bedeutensten humanpathogenen Keime. Bis heute sind durch Pneumokokken hervorgerufene Erkrankungen wie Mittelohrentzündungen, Entzündungen der Nasennebenhöhlen, Pneumonien, Bakteriämien und Meningitiden in der ganzen Welt vorherrschend vertreten. Man geht davon aus, dass in den Industrieländern jährlich 10 bis 20 von 100000 Personen $^{1}$ an einer invasiven Pneumokokkeninfektion (engl. invasive pneumococcal disease (IPD)) erkranken (Elberse et al. 2012; Helferty et al. 2013) und jährlich zwei Millionen Menschen weltweit daran versterben (Herold 2016). Vor allem Kleinkinder bis zum Alter von zwei Jahren und Personen über 65 Jahre sind besonders gefährdet durch das Bakterium zu erkranken. Es ist weltweit der am meisten nachgewiesene Erreger bei einer ambulant erwobenen Pneumonie (engl. community-acquired pneumonia (CAP)) sowie bei bakteriellen Meningitiden bei Kindern, Jugendlichen und Erwachsenen. Im Falle von einer schweren Pneumonie kommt es oft zu einer lebensbedrohliche Bakteriämie (Burman et al. 1985; Lee et al. 1991).

S. pneumoniae wurde erstmals 1880 von G.M. Sternberg und L. Pasteur isoliert. Seither spielte es eine wichtige Rolle bei der Erforschung fundamentaler biologischer Mechanismen und bei der Entwicklung der antimikrobiellen Therapie. Mit der Erfindung der Antibiotika konnte die Mortaliät von Pneumokokkenerkrankungen deutlich gesenkt werden. Seit der Zunahme von Resistenzen liegt das Augenmerk vor allem auf der Entwicklung wirksamer Impfstoffe (Austrian 1999).

\subsection{Morphologie und laborchemische Eigenschaften}

S. pneumoniae ist ein ovales, grampositives Bakterium. Die Größe der Pneumokokken beträgt in der Regel 1,2 bis 1,8 $\mu \mathrm{m}$. Durch ihre meist paarförmige Lagerung werden sie auch als Diplokokken bezeichnet. Sie gehören zur Gattung Streptococcus. Bei Wachstum auf Blutagar bilden sie eine $\alpha$-Hämolyse. Die roten Blutzellen des Agars werden hierbei durch das Bakterium partiell lysiert. Dadurch entsteht ein grünlicher bis bräunlicher Hof um die Kolonien (Hahn et al. 2005).

\footnotetext{
${ }^{1}$ Aus Gründen der besseren Lesbarkeit wird in dieser Dissertation die Sprachform des generischen Maskulinums angewandt. Es wird an dieser Stelle darauf hingewiesen, dass die ausschließliche Verwendung der männlichen Form geschlechtsunabhängig verstanden werden soll.
} 
Die Anzucht von Pneumokokken kann sowohl unter aeroben als auch unter anaeroben Bedingungen erfolgen. Dabei begünstigen 5 bis $10 \%$ ige $\mathrm{CO}_{2}$-Atmosphäre bzw. anaerobe Bedingungen das Wachstum (fakultativer Anaerobier). Das Wachstums- und Temperaturoptimum liegt bei $37^{\circ} \mathrm{C}$. Pneumokokken sind empfindlich gegenüber Kälte, sauren und alkalischen pH-Werten und Austrocknung. Außerhalb eines Wirtes sterben sie unter suboptimalen Bedingungen schnell ab. Die präanalytische Zeit sollte nach Probenentnahme daher nicht über vier Stunden liegen (Höffken et al. 2010).

Zur mikrobiologischen Unterscheidung von anderen $\alpha$-hämolysierenden Streptokokken kann ein Optochintest durchgeführt werden. Hierbei wird ein Filterplättchen, das mit $5 \mu \mathrm{g}$ Optochin (Ethylhydrocuprein-Hydrochlorid) beladen ist, auf die zuvor auf ColumbiaBlutagar ausgestrichene Kolonien gelegt und weitere 18 bis 24 Stunden bei 35 bis $37^{\circ} \mathrm{C}$ in $\mathrm{CO}_{2}$-Atmosphäre inkubiert. Wird das Wachstum der Streptokokken um das Optochinplättchen herum gehemmt und kommt es zu einer Ausbildung eines Hemmhofs (>5 mm), ist dies ein positiver Nachweis für S. pneumoniae (Bowen et al. 1957).

Die meisten Pneumokokken sind von einer Polysaccharidkapsel umgeben. Aufgrund des unterschiedlichen Aufbaus der Polysaccharidkapseln wird S. pneumoniae in verschiedene Serotypen eingeteilt. Bisher wurden 90 Serotypen beschrieben (Pletz et al. 2008). Die Einteilung erfolgt über eine dänische oder amerikanische Nomenklatur. In der dänischen, die sich weltweit durchgesetzt hat, werden die Serotypen nach strukturellen und antigenetischen Eigenschaften in Zahlengruppen zusammengefasst und in diesen Gruppen zudem durch zugeordnete Buchstaben voneinander unterschieden, z. B. Serotyp 6A und Serotyp 6B. In der amerikanischen Nomenklatur wurden die Serotypen nach dem Entdeckungszeitpunkt durchnummeriert. Hier entspricht demnach der Serotyp 6A dem Serotyp 6 und der Serotyp 6B dem Serotyp 26 (Alonso De Velasco et al. 1995).

\subsection{Virulenz}

Die Virulenz der einzelnen Serotypen von S. pneumoniae wird vor allem durch die Struktur und den Aufbau der Polysaccharidkapsel bestimmt. Die Polysaccharidkapsel schützt das Bakterium besonders vor der Phagozytose durch Leukozyten und hemmt die Aktivierung alternativer Komplementkaskaden (Chudwin et al. 1985).

Neben der Polysaccharidkapsel besitzten Pneumokokken weitere Virulenzfaktoren, von denen die meisten an der Oberfläche der Zelle lokalisiert sind.

Das Enzym Neuraminidase erzeugt die Gewebezerstörung des Wirtes. Dadurch werden Oberflächenrezeptoren auf dem Wirtsgewebe freigelegt. Dies widerum ermöglicht den Pneumokken eine Anhaftung an das Gewebe und führt somit zu einer Zunahme der 
Besiedlung (Andersson et al. 1983). Zudem wird die Viskositiät des Schleimes im Pulmonalraum herabgesetzt. Dies ermöglicht eine Erhöhung der Kolonisierung durch $S$. pneumoniae (Lock et al. 1988).

Durch eine Unterdrückung der klassischen Komplementaktivierung durch das Pneumokokkenoberflächenprotein A (PspA) und der alternativen Komplementaktivierung durch das Pneumokokkenoberflächenprotein C (PspC) wird ebenfalls die Immunantwort des besiedelten Wirtes gehemmt und somit eine Expansion der Bakterien möglich (Croney et al. 2013).

Ein weiterer bedeutender Virulenzfaktor ist das Pneumolysin. Es hemmt die Funktion von Lymphozyten und zerstört Endothelzellen (Ferrante et al. 1984). Somit können die Bakterien in das Wirtsgewebe eindringen und sich von dort systemisch ausbreiten (Rubins et al. 1992). Zudem trägt es zur Zerstörung der Blut-Hirn-/Blut-Liquorschranke bei. Dies scheint auch ein bedeutender Faktor bei der Entstehung einer Pneumokokkenmeningitis zu sein (Zysk et al. 2001).

Alle Serotypen sind potentiell pathogen. Die Häufigkeit, mit der verschiedene Serotypen invasive Erkrankungen auslösen, variiert allerdings stark. Ortqvist et al. (2005) haben in drei großen Studien aus drei verschiedenen Ländern, bei denen zwischen 5000 und 10000 Blutproben von Patienten mit invasiven Infektionen auf Pneumokokken untersucht wurden, miteinander verglichen. Hierbei zeigte sich, dass 64 bis 77 verschiedene Serotypen nachgewiesen werden konnten, wobei die Prävalenz jedes einzelnen Serotyps meistens sehr niedrig ausfiel. Eine vierte Studie, die 13616 Pneumokokkenisolate aus aller Welt auswertete, ergab, dass die zehn am häufigsten nachgewiesenen Serotypen einen Anteil von 67,7\% von allen nachgewiesenen Serotypen ausmachten (Robbins et al. 1983). Fasste man davon die 30 Serotypen mit der höchsten Prävalenz zusammen, machten diese Serotypen sogar 91,5\% aller nachgewiesenen Serotypen aus (Ortqvist et al. 2005).

In einer Studie aus Deutschland wurden Daten von verschiedenen Serotypen, durch die es zu einer invasiven Pneumokokkenerkrankung (IPD) kam, über einen Zeitraum von 17 Jahren ausgewertet. Sowohl bei Kindern als auch bei Erwachsenen war der Serotyp 14 der am häufigsten nachgewiesene Serotyp. Bei Kindern waren zudem, in abnehmender Prävalenz, die Serotypen 1, 6B, 19F, 23F und 7F vertreten. Bei Erwachsenen führten dagegen vorwiegend die Serotypen 3, 7F, 1, 4 und $23 \mathrm{~F} \quad \mathrm{zu}$ invasiven Pneumokokkenerkrankungen (Imöhl et al. 2010). Auch Studien aus England, Dänemark und Belgien erbrachten den Nachweis der gleichen Häufigkeitsverteilung der verschiedenen Serotypen bei Kindern (Foster et al. 2008; Konradsen und Kaltoft 2002; Flamaing et al. 
2008). Allerdings gibt es signifikante zeitliche Variationen bei der Prävalenz der verschiedenen Serotypen. Zum Beispiel zeigte Imöhl et al. (2010) einen signifikanten Anstieg der Prävalenz von Serotyp 1 und 7F seit Beginn dieses Jahrhunderts auf. Diese Ergebnisse decken sich mit einer Studie aus Spanien bei der Serotypbestimmungen in Fällen von invasiven Pneumokokkenerkrankungen zwischen 1979 und 2007 durchgeführt wurden (Fenoll et al. 2009). Auch der Serotyp 19A wurde in den letzten Jahren zunehmend bei Erkrankten nachgewiesen (Hicks et al. 2007; Reinert 2009). Warum die Prävalenzen der verschiedenen Serotypen deutlich variieren, ist letztendlich noch nicht vollständig verstanden. Eine Veränderung in den Häufigkeitsverteilungen wurde auch schon vor Einführung der Impfstoffe gegen Pneumokokken beobachtet. Verschiedene Gründe wie Veränderungen in den sozioökonomischen Umständen, die zunehmende Antibiotikaeinnahme und Resistenzentwicklungen, unterschiedliche Immunkompetenzen in verschiedenen Populationen, altersabhängige Variationen sowie starke Schwankungen der Nachweisraten in Blutkulturen werden dabei aufgeführt (Feikin und Klugman 2002). Seit Einführung der Routineimpfung gegen Pneumokokken für Kinder unter zwei Jahren ist in Deutschland und anderen Ländern der Anteil von invasiven Pneumokokkeninfektionen durch die in dem Impfstoff enthaltenen Serotypen signifikant gefallen (Fenoll et al. 2009; Jacobs et al. 2008; Rückinger et al. 2009). Andererseits nimmt der Anteil an Erkrankungen durch Stämme, die nicht durch Impfungen abgedeckt sind, zu (Kellner et al. 2009; Fenoll et al. 2009).

\subsection{Asymptomatische Besiedlung}

Eine Besiedlung des Mund-Nasen-Rachen-Raums mit S. pneumoniae ist in der Bevölkerung weit verbreitet und verläuft in den meisten Fällen asymptomatisch. Viele Studien haben sich in den letzten Jahrzehnten damit beschäftigt, Besiedlungsraten und Faktoren, die eine Besiedlung begünstigen, zu ermitteln. Es zeigte sich, dass bei Kindern vor allem das Alter, die Unterbringung in Kindertagesstätten, eine hohe Bevölkerungsdichte, die Anzahl der Familienmitglieder und Geschwister, der Nikotinabusus in der Familie und eine vorherige Antibiotikaeinnahme eine nasopharyngeale Besiedlung mit S. pneumoniae beeinflussen (Bogaert et al. 2004b; García-Rodríguez und Martínez 2002). Die Besiedlungraten waren im Frühling höher (Korona-Glowniak und Malm 2012; Marchisio et al. 2001) und eine Besiedlung erfolgt häufig bereits im ersten Lebensjahr (Faden et al. 1997).

Die höchsten Besiedlungsraten fand man bei Kindern zwischen dem zweiten und dritten Lebensjahr. Bis zu 75\% der Kinder waren besiedelt. Danach fiel die Anzahl der asymptomatisch besiedelten Individuen bis zum Erwachsenenalter kontinuierlich ab 
(Assefa et al. 2013; Bogaert et al. 2004a; Borer et al. 2001; Christenson et al. 1997; Gunnarsson et al. 1998). Kinder waren dabei vor allem mit den Serotypen 6, 9, 19 und 23 besiedelt (Bogaert et al. 2001; Borer et al. 2001). Andere Studien hingegen zeigten auch eine häufige Besiedlung mit Serotyp 14 oder Serotyp 11 statt mit Serotyp 9 auf (Syrjänen et al. 2001; Varon et al. 2000). Die Prävalenz wird folglich nicht nur durch die oben genannte Faktoren beeinflusst, sondern variiert auch geographisch und zeitlich (Feikin und Klugman 2002). Besiedlungen mit bis zu vier verschiedenen Serotypen im Jahr wurden beschrieben. Andere Kinder machen widerum keine Besiedlungphase durch (Raymond et al. 2000; St Sauver et al. 2000). Der Besiedlungszeitraum beträgt im Durchschnitt ein bis vier Monate. Es gibt jedoch auch Besiedlungen, die länger andauern können. Das wurde vor allem bei Serotypen, die nur eine schwache Immunreaktion auslösen wie z. B. bei Serotyp 6 und 23, beobachtet (Ekdahl et al. 1997).

Studien über die Prävalenz der Besiedlung des nasopharyngealen Raumes bei Erwachsenen gibt es weitaus weniger. Es zeigten sich hier deutlich geringere Besiedlungsraten mit Werten zwischen 1\% und 6,4\% (Abdullahi et al. 2008; Jousimies-Somer et al. 1989; Palmu et al. 2012; Ridda et al. 2010). In einer Studie von Regev-Yochay et al. wurden nasopharyngeale Abstriche von 1300 Erwachsenen und 404 Kindern aus einer Population untersucht. Lediglich 4\% der Erwachsenen waren mit S. pneumoniae besiedelt. Bei den Kindern hingegen wurde bei 54\% eine Besiedlung nachgewiesen (Regev-Yochay et al. 2004). Auch die Besiedlungsdauer mit circa zwei bis vier Wochen ist bei Erwachsenen in der Regel wesentlich kürzer als bei Kindern (Ekdahl et al. 1997).

\subsection{Erkrankungen durch $S$. pneumoniae}

Auch wenn S. pneumoniae ein Keim der normalen nasopharyngealen Flora sein kann, wie häufig vor allem bei Kindern nachgewiesen, so können sich die Pneumokokken von dort ausbreiten und Pneumokokkeninfektionen verursachen. Breiten sich die Pneumokokken vom Nasopharynx in die Eustachische Röhre und weiter in die Ohrhöhle aus, kann dies zu einer Otitis media führen. Gelangen sie hingegen in die unteren Atemwege und expandieren in die Lungenalveolen, kommt es zu einer Pneumonie. Vor allem für betagte Menschen ist eine Pneumonie lebensbedrohlich. Bei Invasion der Bakterien in die Blutbahn steigt die Letalität signifikant an. In zwei Studien konnte dies unabhängig von Behandlung und Risikofaktoren aufgezeigt werden. Bei den über 65-jährigen Individuen mit einer bakteriämischen Pneumonie war die 15-Tages-Letaltät sowie 30-Tages-Letalität während der stationären Behandlung im Vergleich zu der Gruppe ohne Bakteriämie signifikant höher (Capelastegui et al. 2014; Musher et al. 2000). 
Eine bakterielle Meningitis entsteht unter anderem durch Überwindung der Blut-Hirn/Blut-Liqourschranke von Bakterien und Eindringen in den Subarachnoidalraum. $S$. pneumoniae ist im Erwachsenenalter in den wesentlichen Ländern der Haupterreger für eine bakterielle Meningitis und besitzt im Vergleich zu anderen Erregern eine sehr hohe Letalität (van de Beek et al. 2004).

\subsection{Risikofaktoren}

Ein bedeutender Risikofaktor an einer Pneumokokkeninfektion zu erkranken, ist das Alter. Vor allem Kinder im Alter unter zwei Jahren sowie alte Menschen sind besonders gefährdet. Im Alter ist hierfür nicht nur die Immunseneszenz ein entscheidender Faktor, sondern auch anatomische Veränderungen, wie die Abnahme des Hustenreflexes oder der Produktion von Magensäure, spielen eine Rolle (Gavazzi und Krause 2002). Chronischer Alkoholabusus, chronische Lungenerkrankungen (COPD, Asthma), Nikotinabusus, Herzerkrankungen, Demenz und Unterbringung in einem Pflegeheim sind bei Erwachsenen weitere Risikofaktoren (Koivula et al. 1994; Lipsky et al. 1986; Watanakunakorn und Bailey 1997; Yoshikawa und Marrie 2000). Zudem erkranken Männer häufiger an invasiven Pneumokokkeninfektionen (Burman et al. 1985; Kuikka et al. 1992; Scott et al. 1996). Eine Ursache hierfür ist bisher unklar. Da Alkoholismus, Nikotinabusus und chronische Lungenerkrankungen in der männlichen Bevölkerung häufiger vorkommen, könnte dies eine häufigere Erkrankung des männlichen Geschlechts erklären (Sankilampi et al. 1997). Patienten mit einer Immunsschwäche aufgrund Splenektomie, Hypogammaglobulinämie oder einer HIV-Infektion sind ebenfalls stärker gefährdet durch Pneumokokken zu erkranken (Bisharat et al. 2001; Hirschtick et al. 1995).

\subsection{Pneumokokkenpneumonie}

Die ambulant erworbene Pneumonie (CAP) ist eine häufige Erkrankung verbunden mit hoher Morbidität und Mortalität. Sie ist definiert als akute Entzündung des Lungenparenchyms bei Menschen, die bis vier Wochen vor Krankheitsbeginn nicht hospitalisiert waren und keine immunsuppressive Therapie erhalten haben. Die Inzidenz ist auch in Deutschland immer noch sehr hoch. Ungefähr 200000 Patienten werden jährlich stationär aufgrund einer CAP in Deutschland behandelt. Die Letalität beträgt bis zu 14\%. Rechnet man hierbei noch die ambulant behandelten CAP dazu, geht man von einer jährlichen Inzidenz von 400000-600000 Fällen aus. Die Letalität liegt mit unter 1\% bei den ambulant behandelten CAP sehr viel niedriger (Höffken et al. 2010). 
S. pneumoniae ist der Keim, der am meisten bei einer CAP nachgewiesen wird. Dabei ist der Nachweis des pathogenen Keimes häufig schwer. In einer deutschlandweiten Studie konnte, aufgrund mangelnder Sensitivität der verfügbaren Methoden oder fehlender Qualitätskriterien bei Probengewinn, nur in 32\% der Fälle ein Keim nachgewiesen werden (Pletz et al. 2011). Durch das Einschließen von invasiven Eingriffen zur Probengewinnung, wie die Durchführung von transthorakalen Feinnadelpunktionen oder Bronchoskopien, konnte in zwei anderen Studien die diagnostische Ausbeute bis auf 60\% gesteigert werden. Zu ergänzen sei, dass hier teilweise auch, ergänzend zu der konventionellen Diagnostik, genetische Analysen und Antigentestungen durchgeführt wurden. S. pneumoniae war in beiden Sudien der Haupterreger (Ishida et al. 1998; Ruiz-González et al. 1999).

Die Inzidenz von Pneumokokkenpneumonien ist im letzten Jahrhundert trotz Einführung von Antibiotika nicht signifikant zurückgegangen und auch die Sterblichkeit konnte trotz Weiterentwicklung der antibiotischen Therapien nicht gesenkt werden (Hippenstiel et al. 2007).

$\mathrm{Ab}$ dem 60. Lebensjahr steigt das Erkrankungsrisiko deutlich an und aufgrund der Zunahme der Population von über 60-Jährigen wird man in den kommenden Jahren mit zunehmenden Fallzahlen rechnen müssen (Ewig et al. 2009; Pletz et al. 2011). Kleinkinder, bei denen die höchsten Besiedlungsraten nachgewiesen wurden, sind dabei das Hauptreservoir. Mit zunehmender Anzahl der Kinder in einem Haushalt steigt das Risiko für Erwachsene an einer Pneumonie zu erkranken (Schnoor et al. 2007).

\subsection{Klinik der Pneumokokkenpneumonie}

Eine Lobärpneumonie durch $S$. pneumoniae verursacht typischerweise einen sehr plötzlichen Erkrankungsbeginn mit Schüttelfrost und hohem Fieber. Meistens besteht Husten und kommt kommt es zur Atemnot. Es wird häufig gelb-grünlicher Sputum produziert und abgehustet. Durch eine Begleitpleuritis kann es zu Thoraxschmerzen und Fortleitung der Schmerzen bis in den Ober- und Unterbauch kommen. Auskultatorisch sind Bronchialatmen, positive Bronchophonie, klingende Rasselgeräusche und positiver Stimmfremitus Hinweise auf eine Pneumonie. Röntgenmorphologisch zeigen sich meist großflächige Transparenzminderungen auf einen Lappen beschränkt, im Sinne einer Lobärpneumonie. Es können aber auch atypische Verteilungen oder Segmentpneumonien vorkommen. Laborchemisch findet sich typischerweise eine Leukozytose mit Linksverschiebung sowie Erhöhung von CRP, BSG und Procalcitonin (Gerok et al. 2007; Herold 2016). 
Vor allem bei älteren Patienten können die charakteristischen Symptome einer Pneumonie fehlen. In einer Studie in den USA wurden von 48 Patienten, die aufgrund einer CAP hospitalisiert und älter als 65 Jahre waren, die Symptome ausgewertet. Die typischen Symptome wie Fieber, Husten und Dyspnoe traten nur bei 56\% auf. 10\% der Patienten zeigten keine dieser Symptome (Harper und Newton 1989). Allgemeine Schwäche, Dehydrierung und Verwirrtheitszustände gehören bei betagten Menschen häufig zu den Symptomen einer Pneumonie (Hof et al. 2013). Die Verläufe sind ebenfalls eher atypisch. Riquelme et al. und Venkatesan et al. beschrieben ein schlechteres Outcome für Patienten, bei denen kein Fieber auftrat (Riquelme et al. 1997; Venkatesan et al. 1990).

Zur Einschätzung des Sterblichkeitsrisikos wurden in den letzten Jahren verschiedene Scores entwickelt. Durchgesetzt hat sich der CRB-65-Score. Anhand des Geisteszustandes $(\mathrm{C}=$ confusion $)$, der Atemfrequenz $(\mathrm{R}=$ respiration $)$, des Blutdrucks $(\mathrm{B}=$ blood pressure $)$ und des Alters kann der Schweregrad einer ambulant erworbenen Pneumonie abgeschätzt werden und ist wegweisend für die weitere Therapie und Behandlung. Dass der Krankheitsverlauf mit der durch den Score erhobene Prognose übereinstimmt, wurde durch Studien bestätigt (Ewig et al. 2009; Pletz et al. 2011).

\subsection{Antibiotische Therapie}

Seit mehr als einem halben Jahrhundert wird Penicillin als Standardbehandlung für Pneumokokkeninfektionen benutzt. Das Medikament der Wahl war bei unkomplizierten Pneumokokkenpneumonien Pencillin V und bei schwereren Verläufen Penicillin G. Aufgrund der in den letzten Jahrzehnten zunehmenden Antibiotikaresistenzen wird die Behandlung von Pneumokkenpneumonien zunehmend komplizierter. Vor allem die Serotypen 6A, 6B, 9V, 14, 19A, 19F und 23F zeigen weltweit eine hohe Resistenzrate auf (Dagan und Klugman 2008).

Resistenzen von S. pneumoniae gegenüber Antibiotika sind in Deutschland erfreulicherweise aktuell noch selten. Die Penicillinresistenz liegt bei unter 3\%. Hierbei handelt es sich zudem um Niedrigresistenzen (minimale Hemmkonzentration $\leq 2 \mathrm{mg}$ ) (Pletz et al. 2011). Ein Therapieversagen bei CAP durch niedrigresistente Pneumokokkenstämme unter Penicillintherapie ist, wie Studien zeigten, nicht zu erwarten (Yu et al. 2003). Auch wenn Resistenzen gegen Makrolide in den letzten Jahren abgenommen haben, sind sie im Vergleich zu den Penicillinresistenzen in Deutschland deutlich häufiger. CAPNETZ-Daten mit von 2002 bis 2008 gesammelten Pneumokokken ergaben im Mittel eine Makrolidresistenz von circa 20,5\%. Bei einer Makrolidmonotherapie sollte deshalb bei fehlendem Ansprechen zeitnah an makrolidresistente Pneumokokken gedacht werden 
(Pletz et al. 2011). Ein ausführliches Antibiogramm muss nicht zwingend vor Therapiebeginn durchgeführt werden. Für die Prognose ist der frühzeitige Beginn der kalkulierten Antibiotikatherapie wichtiger und entscheidend (Hof et al. 2013).

Ambulant erworbene Pneumonien werden heutzutage in Deutschland, wenn der Patient keine Risikofaktoren aufweist und ambulant behandelt werden kann, gemäß den S3Leitlinien mit dem Aminopenicillin Amoxicillin über fünf bis sieben Tage oral behandelt. Alternativ stehen die Makrolide Azithromycin, Clarithromycin und Roxithromycin sowie Doxycyclin zur Verfügung. Eine häufiger auftretende Resistenz gegen Makrolide sollte dabei, wie bereits oben erläutert, beachtet werden. Bei Patienten mit Risikofaktoren (vorherige Antibiotikatherapie, Bewohner von Pflegeheimen, chronische internistische/neurologische Begleiterkrankungen) soll eine Therapie mit einem Betalaktamantibiotikum (Amoxicillin/Clavulansäre, Sultamicillin) über fünf bis sieben Tage oral erfolgen. Hier werden als Alternativen die Flourchinolone Levofloxacin oder Moxifloxacin empfohlen.

Bei hospitalisierten Patienten richtet sich die Wahl des Antibiotikums nach dem Schweregrad der CAP. Zudem müssen die Risikofaktoren für eine Infektion durch $P$. aeruginosa miteinbezogen werden. Mittel der Wahl sind bei unkomplizierten Pneumonien Amoxicillin/Clavulansäure, Ampicillin/Sulbactam, Cefuroxim, Ceftriaxon oder Cefotaxim, alle intravenös verabreicht. Flourchinolone stellen auch hier eine Alternative dar und Makrolide werden zusätzlich je nach Klinik empfohlen. Eine Behandlung mit dem Carbanem Ertapenem soll bei Patienten mit dem Risiko einer Enterobacteriacea-Infektion inklusive ESBL-Bildnern oder bei Patienten, die zuvor bereits eine Penicillin/Cephalosporinbehandlung erhalten haben, durchgeführt werden. Bei schweren Pneumonien wird Pipercillin/Tazobactam, Ceftriaxon, Cefotaxim oder Ertapenem in Kombination mit einem Makrolid empfohlen. Bei septischem Schock oder invasiver Beatmung sollte eine Kombinationstherapie aus einem Betalaktam-Antibiotikum und einem Flourchinolon erfolgen (Höffken et al. 2010).

\subsection{Prävention}

Derzeit sind drei verschiedene Impfstoffe gegen Pneumokokken in der klinischen Praxis erhältlich, der 23-valente Polysaccharidimpfstoff, der 7-valente Konjugatpneumokokkenimpfstoff und der 13-valente Konjugatpneumokokkenimpfstoff. 


\subsubsection{3-valenter Polysaccharidimpfstoff}

Seit 1983 ist eine Impfung aus gereinigten Kapselpolysacchariden für Erwachsene und Kinder über zwei Jahren zugelassen. Der PPSV-23 (Pneumovax 23®) enthält Polysaccharidantigene von 23 Serotypen von $S$. pneumoniae $(1,2,3,4,5,6 \mathrm{~B}, 7 \mathrm{~F}, 8,9 \mathrm{~N}, 9 \mathrm{~V}$, 10A, 11A, 12F, 14, 15B, 17F, 18C, 19A, 19F, 20, 22F, 23F und 33F). Damit sollen 85-90\% der am Meisten verbreiteden Serotypen abgedeckt sein (Bogaert et al. 2004). Die PPSV23Impfung wird als einzelne intramuskuläre Dosis verabreicht. Durch die Impfung werden direkt B-Lymphozyten ohne Einfluss von T-Lymphozyten stimuliert und bilden vor allem IgM-Antikörper. Diese zirkulieren aufgrund ihrer Molekülgröße ausschließlich im Blut und opsonieren dort Pneumokokken, die dadurch von Makrophagen besser phagozytiert und abgetötet werden können. Ein immunologisches Gedächtnis wird dabei nicht gebildet (Hof et al. 2013). In einer Studie bei Erwachsenen wurde die Immunantwort nach Impfung mit PPSV-23 untersucht. Sechs Monate nach Verabreichung der Impfung fielen die Antikörperspiegel aller gemessener Serotypen auf die Ausgangswerte zurück (Musher et al. 2008). In einer anderen Studie konnten vier bis sieben Jahre nach erstmaliger Impfung mit PPSV-23 keine Antikörper gegen die entsprechenden Serotypen mehr nachgewiesen werden (Törling et al. 2003). Aufgrund der immunologischen Eigenschaft bietet diese Impfung, wegen des noch unausgereiften Immunsystems, keinen Schutz bei Kindern unter zwei Jahren. Zudem kommt es bei dieser Immunreaktion zu keiner Bildung von IgG- bzw. IgA-Antikörpern. Somit entsteht keine lokale Immunität und ein positiver Effekt auf eine nasopharyngeale Besiedlung besteht nicht (Herva et al. 1980). Auch wenn der Schutz vor einer Pneumokokkenpneumonie durch die PPSV-23 häufig disskutiert wird, schützt sie durch die humorale Immunität vor einer Pneumokokkensepsis, die eine häufige tödliche Komplikation darstellt (Mykietiuk et al. 2006). Die Impfraten bei alten Menschen sind im Gegensatz zu Kindern niedrig. Bei den 65-bis 79-Jährigen wurde durch die bevölkerungsrepräsentative Studie zur Gesundheit Erwachsener in Deutschland (DEGS1) eine Impfrate von 31,4\% ermittelt (Poethko-Muller und Schmitz 2013). Personen ab 60 Jahren, Menschen ab 16 Jahren mit chronischen Erkrankungen sowie Personen mit Berufen bei denen eine Exposition gegenüber Metall-und Schweisßrauchen besteht, sollen in Deutschland nach STIKO eine Impfung mit PPSV-23 erhalten und diese alle sechs Jahre auffrischen (Ständige Impfkommission 2018).

\subsubsection{7-valenter Konjugatpneumokokkenimpfstoff}

Der 7-valente Konjugatpneumokokkenimpfstoff ist ein konjungierter Impfstoff, bei dem Fragmente aus Kapselpolysacchariden von sieben verschiedenen Pneumokokkenserotypen 
(4, 6B, 9V, 14, 18C, 19F, 23F) an einen Proteinträger gebunden sind. Das Trägerprotein CRM197 ist eine nicht toxische Form des Diphterietoxins. Als Adjuvans enthält der Impfstoff Aluminiumphosphat. Er ist seit dem Jahr 2000 in den USA zugelassen und inzwischen in mehr als 90 Ländern verfügbar. Die PCV-7 (Prevenar ${ }^{\circledR}$ ) erzeugt im Gegensatz zur PPSV-23 auch eine Immunität bei Kindern unter zwei Jahren und wird seit 2006 als Routine-Impfung von der STIKO in Deutschland empfohlen. Bei der PCV-7 werden immunologisch nicht nur B-Zellen, sondern auch T-Zellen stimmuliert, was die Prduktion von IgG- und IgA-Antikörpern anregt. Das führt zu der Herausbildung eines immunologischen Gedächtnisses und bewirkt eine lokale IgA-getragene Immunität im Bereich des Nasopharynx (Pletz et al. 2008). Die Einführung der Routineimpfung bei Kindern mit PCV-7 führte nicht nur zur Reduktion von invasiven Pneumokokkeninfektionen bei Kindern, sondern es konnte auch ein Abfall der invasiven Pneumokokkeninfektionen bei Erwachsenen nachgewiesen werden (Whitney et al. 2003). Da die Besiedlungsraten bei den Kindern durch die in der Impfung enthaltenen Serotypen reduziert wurden, erfolgte auch keine Ansteckung nicht geimpfter Personen mit diesen Serotypen. Somit konnte eine Herdenimmunität erzeugt werden, d. h. durch Impfung einer bestimmten Bevölkerungsgruppe wird die Erkrankungshäufigkeit in der gesamten Bevölkerung reduziert (Pletz et al. 2008). Es zeigte sich jedoch auch, dass Erkrankungen zunahmen, die durch Serotypen hervorgerufen wurden, die nicht durch die PCV-7 abgedeckt wurden. In Studien wurde nach Einführung der Routineimpfung mit PCV-7 bei Kindern eine signifikante Zunahme von invasiven Pneumokokkeninfektionen durch Serotypen, die nicht in der PCV-7 enthalten waren, bei Kindern als auch bei Erwachsenen nachgewiesen (Hicks et al. 2007; Kellner et al. 2009).

\subsubsection{3-valenter Konjugatpneumokokkenimpfstoff}

Seit 2009 wurde die PCV-7 durch eine 13-valente PCV (Prevenar 13®) in Deutschland abgelöst. Diese enthält die Serotypen 1, 3, 4, 5, 6A, 6B, 7F, 9V, 14, 18C, 19A, 19F und 23F und ebenfalls wie der heptavalente Impfstoff Aluminiumphosphat als Adjuvans sowie das Trägerprotein CRM197. Der Impfstoff wurde um die sechs Serotypen 1, 5, 7F, 3, 6A und 19A erweitert, die nach Einführung der PCV-7 eine steigende Prävalenz zeigten.

Die STIKO empfielt derzeit die Immunisierung von Kindern mit Prevenar 13® mit drei Impfdosen im Alter von zwei, vier und elf bis 14 Monaten. Zudem sollen Menschen mit angeborenem oder erworbenem Immundefekten bzw. Immunsuppression sowie Personen mit anatomisch oder fremdkörper-assoziierten Risiko für eine Pneumokokkenmeningitis 
eine Immunisierung mit PCV-13 gefolgt von PPSV-23 erhalten (Ständige Impfkommission 2018).

\subsection{Fragestellung}

Im Falle der Pneumokokken, der wichtigsten bakteriellen Erreger von Infektionen des Respirationstrakts, führte eine systematische Impfung von Kindern mit Konjugatimpfstoffen zu einem signifikanten Abfall invasiver Pneumokokkeninfektionen. Auch nicht Geimpfte scheinen davon zu profitieren (Pilishvili et al. 2010; van der Linden et al. 2015). Kommt es jedoch zur Erkrankung bleibt die Letalität vor allem bei betagten Menschen weiterhin sehr hoch. Dies betrifft sowohl die invasiven als auch nicht invasiven Pneumokokkeninfektionen (Ewig et al. 2012). Serotypen, die früher nur einen kleinen Teil der invasiven Pneumokokkeninfektionen ausmachten, scheinen an Bedeutung zuzunehmen (Hicks et al. 2007). Antibiotikaresistenzen sind in Deutschland zwar noch selten, in anderen Ländern sind diese jedoch bedeutend höher (Pletz et al. 2011). Inwieweit eine Herdenimmunität einen positiven Einfluss auf die Resistenzentwicklung hat, bleibt derzeit noch offen. Damit Kliniker letztendlich nicht Infektionen gegenüber stehen, die durch multiresistente Keime für die keine effektive antimikrobiellen Therapien zur Verfügung stehen, verursacht werden, ist es umso wichtiger die Einführung und Weiterentwicklung von präventiven Strategien zusammen mit neuen Antibiotika zu unterstützen.

Diese Arbeit soll durch die Entnahme und Kolonisierung von Rachenabstrichen Aufschluss über Besiedlungshäufigkeiten durch $S$. pneumoniae bei hospitalisierten, geriatrischen Patienten bringen. Zur weiteren Differenzierung soll eine Bestimmung der Serotypen und Antibiotikaresistenzen erfolgen. Ziel dieser Arbeit ist es exakte Daten zur Epidemiologie der Besiedlung mit S. pneumoniae des Respirationstrakts in Deutschland bei alten (75 bis 90 Jahre) und hochbetagten Menschen ( $>90$ Jahre) zu bekommen. Desweiteren sollen Zusammenhänge zwischen den Besiedlungshäufigkeiten und vorheriger Immunisierung durch PPV-23, antibiotischer Therapie, klinischer Symptomatik, Komorbiditäten und Risikofaktoren herausgearbeitet werden. 


\subsection{Patientenkollektiv}

Die Rachenabstriche wurden im Zeitraum vom 29. März 2011 bis zum 22. Juni 2011 entnommen. Das Kollektiv, von dem Proben entnommen wurde, setzte sich aus geriatrischen Patienten zusammen, die sich zu diesem Zeitraum aufgrund unterschiedlicher Erkrankungen in stationärer Behandlung in der Geriatrischen Abteilung des Evangelischen Krankenhaus in Göttingen-Weende befanden. Das Evangelische Krankenhaus GöttingenWeende ist ein Krankenhaus der Grund- und Regelversorgung mit, zum damaligen Zeitpunkt, 448 Betten in Niedersachsen. Es ist ein Lehrkrankenhaus der Universitätsmedizin Göttingen. Das Geriatrische Zentrum besaß während des Studienzeitraumes 90 Betten. In diesem Zeitraum konnte bei 185 Patienten ein Rachenabstrich zur weiteren Kultivierung gewonnen werden. Bei 15 Patienten war eine Probenentnahme der Rachenschleimhaut aufgrund Ablehnung an der Teilnahme der Studie oder aufgrund starker körperlicher und geistiger Einschränkungen nicht möglich. Der Großteil, die in diesem Zeitraum in der Abteilung in stationärer Behandlung waren, konnte in die Studie aufgenommen werden. Da wir vor Beginn der Studie von einer Besiedlungsrate von circa 20\% ausgingen und es unser Ziel war 30 bis 40 positive Kulturen zu bekommen, sollten bei circa 200 Individuen Proben entnommen werden.

\subsection{Datenerhebung}

Vor Beginn der Studie wurde ein Fragebogen zusammengestellt, der ergänzend zu der Probenentnahme von Studienteilnehmern ausgefüllt wurde. Der Fragebogen (siehe Anhang) enthält Angaben über Geburtsjahr, Geschlecht, Haupt-und Nebendiagnosen, Ernährungsform, Vorbehandlungen mit Auswirkungen auf den derzeitigen Gesundheitszustand, Impfstatus, Antibiotikaeinnahme im Zeitraum von vier Wochen vor dem aktuellen stationären Aufenthalt, andere Therapiemaßnahmen, aktuelle Medikation, aktuelle klinische Symptome, Allgemeinzustand und Pflegebedarf, Mundhygiene, klinischer Untersuchungsbefund der Mundhöhle sowie Verdauung und Ausscheidung. Mit Hilfe dieses Fragenbogens konnten wir Daten sammeln, die aufgrund vorheriger Literaturrecherchen und Hypothesen einen möglichen Zusammenhang $\mathrm{zu}$ einer Rachenbesiedlung mit S. pneumoniae vermuten ließen. 
Für die korrekte Beantwortung bestimmter Fragen wurden die Patientenakten von jedem Studienteilnehmer hinzugezogen.

\subsection{Ausfüllen der Fragenbögen}

Um das Ausfüllen der Fragebögen zu erleichtern und Fehler bei der Datenerhebung zu vermeiden, erfolgte dies im Rahmen eines Interviews vor Entnahme des Rachenabstriches. Somit konnte auf Widersprüche und Unklarheiten direkt eingegangen und die vollständige und korrekte Beantwortung des Fragebogens gesichert werden.

\subsection{Probenentnahme}

Die Entnahme der Rachenabstriche erfolgte nach nach Aufklärung über Komplikationen, die bei der Gewinnung der Proben hätten auftreten können, und nach schriftlicher Zustimmung zur Studienteilnahme durch die Patienten. Ein Formblatt zur Aufklärung der Studieninhalte und die Einwilligungserklärung wurden den Studienteilnehmer ausgehändigt. Die Probenentnahme und Studiendurchführung wurde durch die Ethikkommission der Universitätsmedizin Göttingen genehmigt (Antragsnummer 4/7/10).

Die Probenentnahme wurde im Laufe des Vormittags in mindestens $30 \%$ iger Oberkörperlagerung durchgeführt. Mit einem Abstrichtupfer wurde über beide Rachentonsillen und die Rachenhinterwand gestrichen und somit eine Probe der Rachenschleimhaut gewonnen. Der Abstrichtupfer wurde anschließend ohne weitere Kontamination in ein steriles Gefäß aus Polypropylen mit Amies Agar Gel (Transystem ${ }^{\circledR}$, Hain Lifescience, Nehren, Germany) gegeben. Das Versandgefäß wurde mit einer anonymen Probennummer versehen. Die Probennummer ermöglichte die Zuordnung des Kultivierungsbefundes zu dem Fragebogen.

\subsection{Probentransport}

Der Probentransport erfolgte ohne den Einfluss großer Temperaturschwankungen unverzüglich in das Institut für Klinische Mikrobiologie der Universitätsmedizin Göttingen (Leiter: Prof. Dr. U. Groß).

\subsection{Kultivierung und Bebrütung}

Das gewonnene Material wurde innerhalb von vier Stunden nach Probenentnahme unter Durchführung eines fraktionierten Drei-Ösen-Austrichs auf Kochblutagar (Biomerieux, 
Nürtingen, Deutschland) und Columbia-Schafblutagar (Biomerieux, Nürtingen, Deutschland) aufgetragen.

Die Bebrütung erfolgte in $5 \%$ iger $\mathrm{CO}_{2}$-Atmosphäre bei 35 bis $37^{\circ} \mathrm{C}$ im Brutschrank (Memmert, Schwabach, Deutschland) über 48 Stunden. Nach 24 Stunden erfolgte eine erste Ablesung. Nach 48 Stunden wurde erneut abgelesen und die Ergebnisse dokumentiert.

\subsection{Ablesung des Bakterienwachstums}

Die Ablesung wurde mit Hilfe ausgebildeter und erfahrener Medizinisch-Technischer Assistentinnen des Instituts für Klinische Mikrobiologie der Universitätsmedizin Göttingen durchgeführt. Die gewachsenen Bakterienkulturen wurden nach Morphologie, Wachstumsmerkmalen und Hämolyseverhalten differenziert und das Ergebnis in einem Befundbericht dokumentiert.

Kulturen, welche die Merkmale von S. pneumoniae aufwiesen (siehe 2.7.1), wurden isoliert und subkultuviert. Nach Subkultivierung erfolgte zur Unterscheidung von S. pneumoniae und anderen Streptokokken die Durchführung eines Optochin-Tests..

\subsubsection{Kulturelle Merkmale von S. pneumoniae}

Pneumokokken wachsen zu grau-weißlichen, glatten und runden Kolonien. Nach einer Bebrütungszeit von 24 Stunden zeigen sie eine charakteristische Vergrünung der Kolonien, die durch ihre Fähigkeit eine $\alpha$-Hämolyse durchzuführen zustande kommt. Nach 48 Stunden beginnt die Autolyse der Bakterien, die als zentrale Eindellung in der Kolonien sichtbar wird.

\subsubsection{Optochintest}

Die Empfindlichkeitsprüfung gegenüber Optochin ist eine einfache Methode zur Unterscheidung von $S$. pneumoniae und anderen vergrünenden Streptokokken. Optochin ist ein Chininderivat aus der Rinde des Chinabaumes. Es aktiviert die Muraminidase der Pneumokokken und bewirkt eine autolytische Auflösung der Mureinschicht der Zellwand. Das Wachstum von S. pneumoniae wird dadurch gehemmt. Ein Filterplättchen, das mit 5 $\mu \mathrm{g}$ Optochin (Ethylhydrocuprein-Hydrochlorid) beladen ist, wird vor der Bebrütung auf die Kulturen gelegt und führt bei Pneumokokken zu einer Ausbildung eines Hemmhofes, dessen Breite vom Plättchenrand gemessen, mindestens $5 \mathrm{~mm}$ betragen muss (Bowen et al. 1957). 
Nach mindestens 18-stündiger Subkultivierung von Kulturen, die Pneumokokkenmerkmale trugen, wurden fünf Kolonien auf Columbia-Schafblutagar (Biomerieux, Nürtingen, Deutschland) ausgestrichen. Danach wurde mit Hilfe einer Pinzette (Einmalpinzetten, Rettberg, Göttingen, Deutschland) das Optochinplättchen (Oxoid, Wesel, Deutschland) in die Mitte der Agarplatte aufgelegt und über Nacht bei 35 bis $37^{\circ} \mathrm{C}$ unter $5 \%$ iger $\mathrm{CO}_{2}-$ Atmosphäre bebrütet (Brutschrank, Memmert, Schwabach, Deutschland).

S. pneumoniae zeigt nach der Bebrütungszeit einen deutlichen Hemmhoff, dessen Breite vom Optochinplättchenrand mindestens $5 \mathrm{~mm}$ betragen muss um den Test als positiv werten zu können. Andere Streptokokkenarten wachsen bis an den Plättchenrand heran oder bilden nur einen schmaleren Hemmhof.

\subsection{Kontrolle der Methodik}

Um die Durchführung der Methodik und Kultivierung $\mathrm{zu}$ verifizieren wurden Positivkontrollen durchgeführt. Es wurden dafür drei Pneumokokkenstämme der Serotypen D39, R6 und 3 aus dem Labor der Arbeitsgruppe Geriatrische Neuroinfektiologie des Institut für Neuropathologie der Universitätsmedizin Göttingen verwendet. Die Pneumokokkenstämme lagern dort bei $-80^{\circ} \mathrm{C}$ in $0,9 \%$ iger NaCl-Lösung und werden für Forschungzwecke genutzt. Für die Positivproben wurden jeweils $10 \mu \mathrm{lder}$ Testlösung unter sterilen Bedingungen auf den Abstrichtupfer der sterilen Versandgefäße (Transystem, Hain Lifescience, Nehren, Deutschland) pipettiert. Die weitere Vorgehensweise entsprach der Methotik der Auswertung der Rachenabstriche.

\section{Geräte und Materialien}

- Abstrichtupfer mit sterilen Versandgefäß aus Polypropylen angereichert mit Amies Agar Gel (Transystem, Hain Lifescience, Nehren, Deutschland)

- Kochblutagar (Biomerieux, Nürtingen, Deutschland)

- Columbia-Schafblutagar (Biomerieux, Nürtingen, Deutschland)

- Brutschrank (Memmert, Schwabach, Deutschland)

- Einmalpinzetten (Rettberg, Göttingen, Deutschland)

- Optochin-Scheiben 5 ug (Oxoid, Wesel, Deutschland)

- Platinösen/Einmalösen (Sarstedt, Nürmbrecht, Deutschland)

- Einmalpipetten (Eppendorf, Hamburg, Deutschland)

- Selbsterstellte Fragebögen (siehe Anhang) 
- Postitivkontrollen: S. pneumoniae 3, S. pneumoniae D39, S. pneumoniae R6 (Labor der Arbeitsgruppe Geriatrische Neuroinfektiologie, Institut für Neuropathologie, Universitätsmedizin Göttingen, Deutschland) 


\section{Ergebnisse}

Bei 185 Patieten wurden im Zeitraum vom 29. März 2011 bis zum 22. Juni 2011 Rachenabstriche entnommen und diese auf eine Besiedlung mit $S$. pneumoniae untersucht. Bei keinem Patienten konnte eine Pneumokokkenbesiedlung nachgewiesen werden.

\subsection{Alter und Geschlecht}

Es wurden bei 185 Patienten Rachenabstriche entnommen. Davon waren 127 weiblich $(68,6 \%)$ und 58 männlich (31,4\%). Das Alter der Patienten lag zwischen 54 und 101 Jahren. Im Median betrug es 81 Jahre.

\subsection{Hauptdiagnosen und Diabetes mellitus}

Die Hauptdiagnosen, die zu einer stationären Aufnahme in die Geriatrische Abteilung führten, waren bei den Patienten sehr unterschiedlich. Die Einteilung in neun verschiedene Gruppen wurde nach den Hauptdiagnosen durchgeführt. Die Gruppenunterteilung erfolgte nach Lungenerkrankungen, kardialen Erkrankungen, Lebererkrankungen, Niereninsuffizienz, Tumorerkrankungen, neurologischen Erkrankungen, Erkrankungen und Verletzungen des Bewegungsapperats, allgemeinchirurgischen Erkrankungen im Bereich des Abdomens und unklarer Verschlechterung des Allgemeinzustandes. Bei 86 Patienten (46,4\%) führte ein orthopädischer oder unfallchirurgischer Eingriff mit nachfolgenden Komplikationen oder erschwerter Rehabilitation zu einem stationären Aufenthalt (54 hatten verschiedene Frakturen nach Sturzereignissen, 14 kamen nach elektiver Endoprothese des Hüftgelenkes, sieben nach elektiver Endoprothese des Knieglenkes und 11 nach anderen elektiven orthopädischen Eingriffen). Neurologische Ursachen waren bei 36 Patienten (19,6\%) der Aufnahmegrund. 13 Patienten (7,0\%) wurden wegen einer unklaren Verschlechterung des Allgemeinzustandes zur weiteren Abklärung aufgenommen. 15 Patienten (8,1\%) lagen aufgrund einer prolongierten stationären Nachsorgebehandlung nach chirurgischen Eingriffen im Bereich des Abdomens in der Abteilung für Geriatrie. Acht Patienten (4,3\%) litten an einer chronischen Lungenerkrankung. Neun Patienten (4,9\%) waren wegen einer Pneumonie hospitalisiert. Zehn Patienten (5,4\%) waren wegen einer kardialen Erkrankung in stationärer Behandlung. Bei drei Patienten (1,6\%) führten Behandlungen von Tumorerkrankungen zu einer stationären Aufnahme und bei jeweils zwei Patienten (1,1\%) eine Lebererkrankung bzw. eine Niereninsuffizienz. 
Zum Zeitpunkt der Probenentnahmen war bei 39 Patienten $(21,1 \%)$ ein Diabetes mellitus Typ 2 bekannt.

\section{HAUPTDIAGNOSEN}

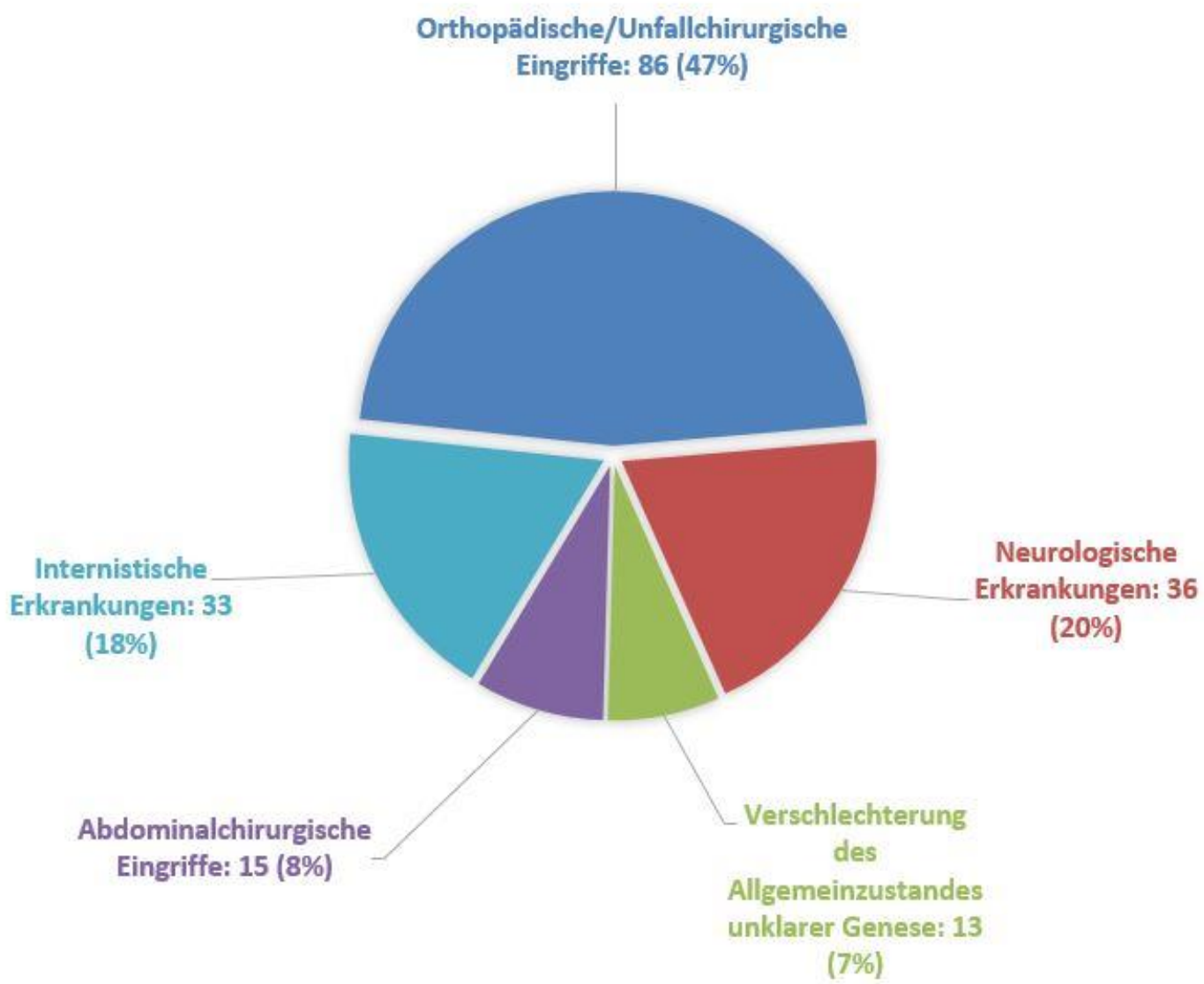

Abbildung 1: Hauptdiagnosen 


\section{HAUPTDIAGNOSEN INTERNISTISCHE ERKRANKUNGEN}

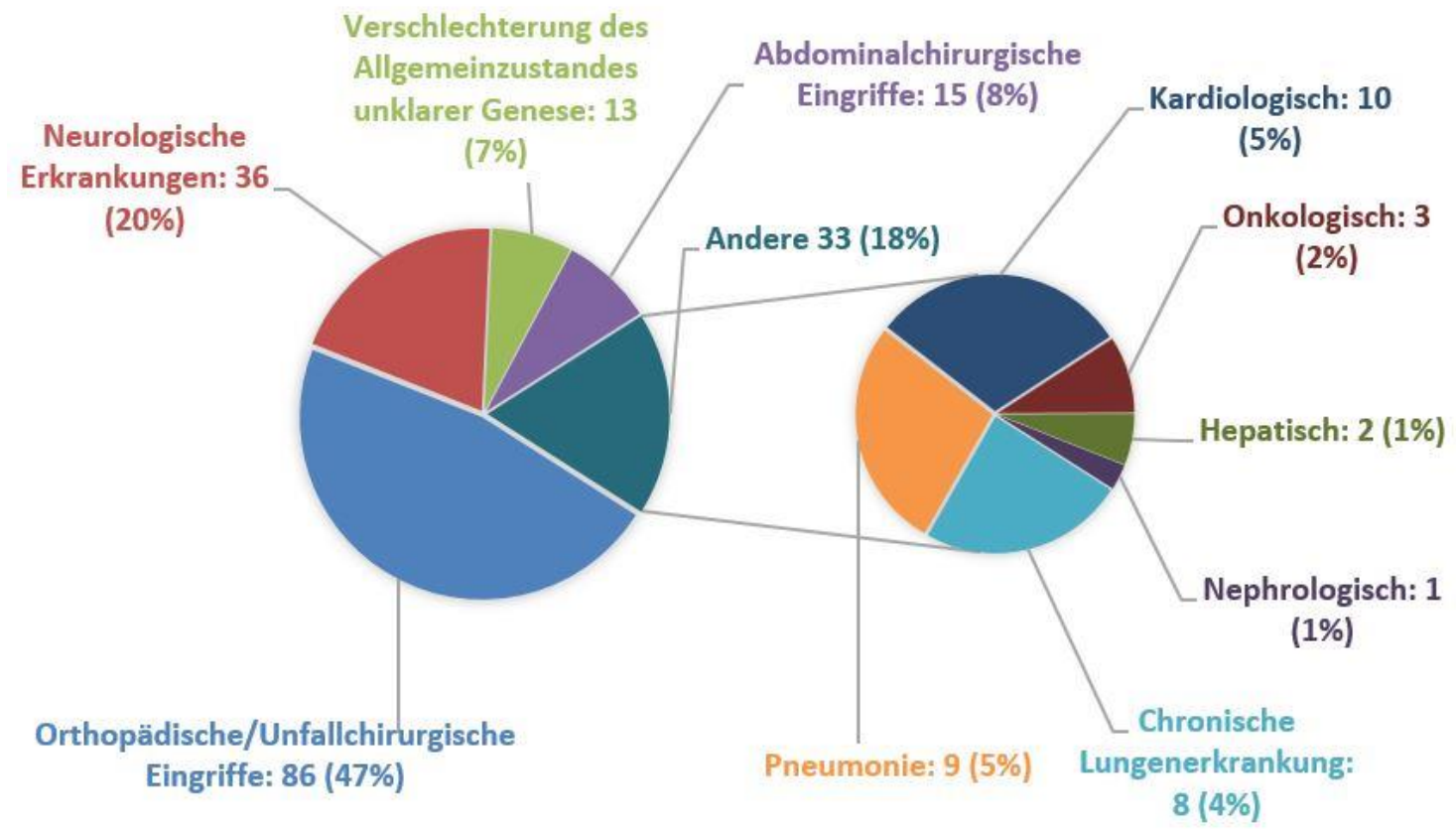

Abbildung 2: Hauptdiagnosen: Internistische Erkrankungen

\section{HAUPTDIAGNOSEN ORTHOPÄDISCHE / UNFALLCHIRURGISCHE ERKRANKUNGEN}

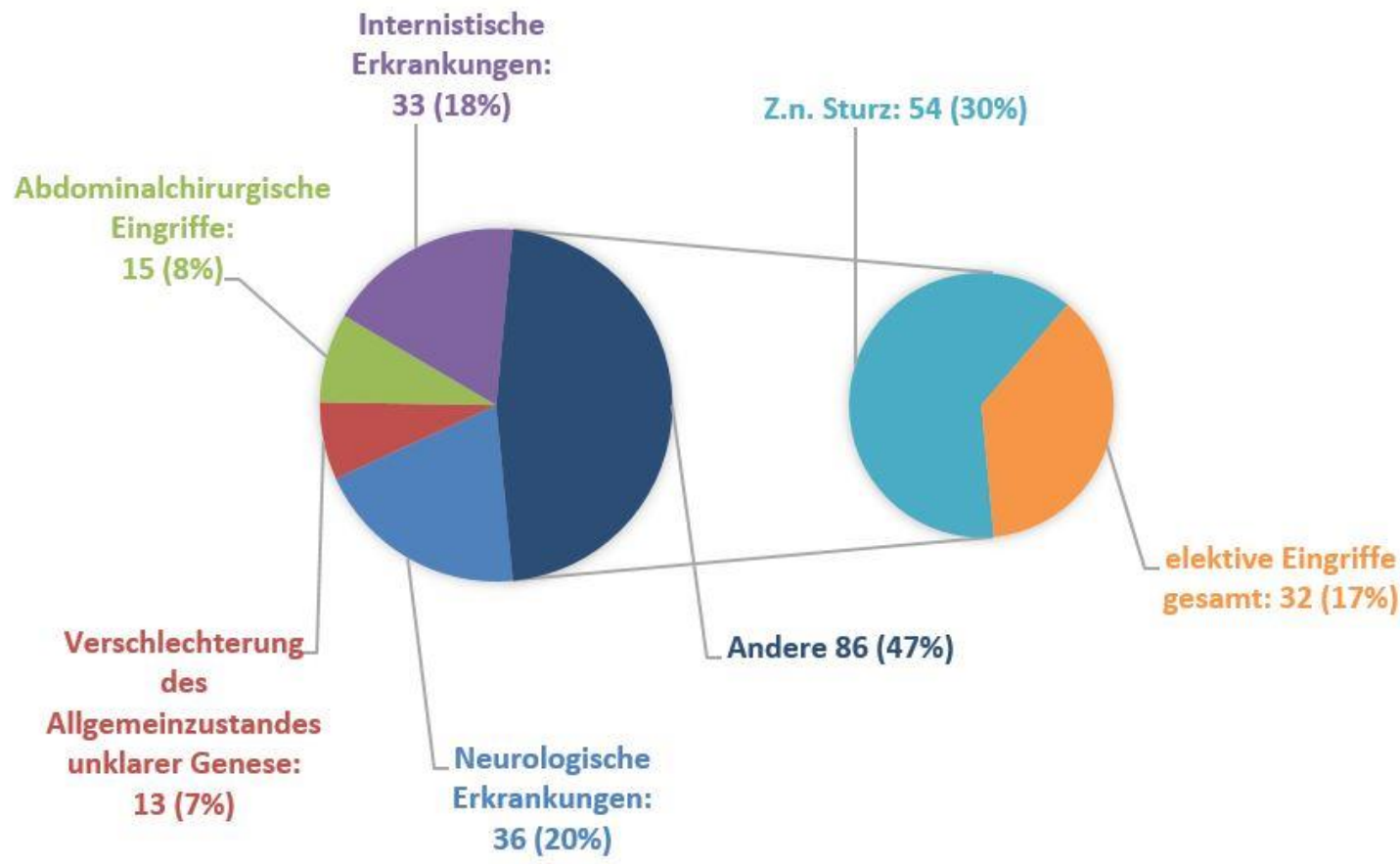

Abbildung 3: Hauptdiagnosen: Orthopädische/unfallchirurgische Erkrankungen 


\section{DIABETES MELLITUS}

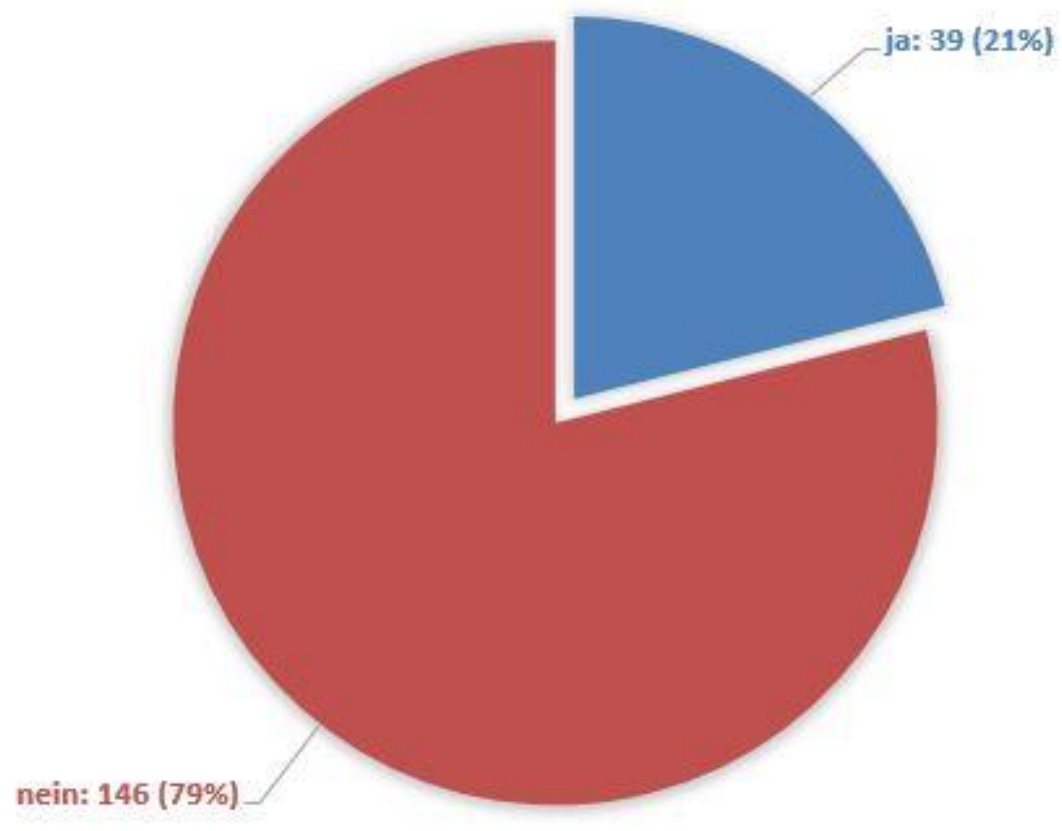

Abbildung 4: Nebendiagnosen: Risikofaktor Diabetes mellitus 


\subsection{Impfstatus}

Insgesammt 33 Patienten $(17,8 \%)$ hatten eine Immunisierung gegen Pneumokokken (PPSV-23) erhalten. 79 Patienten (43,0\%) waren gegen Influenzaviren geimpft. Weder gegen Influenzaviren noch gegen Pneumokokken waren 73 Patienten (39,5\%) geimpft. Unter den 33 Patienten, die eine Pneumokokkenimpfung erhalten hatten, waren 32 Patienten (17,3\%) davon auch gegen Influenzaviren geimpft.

\section{IMPFSTATUS (INFLUENZA/PNEUMOKOKKEN)}

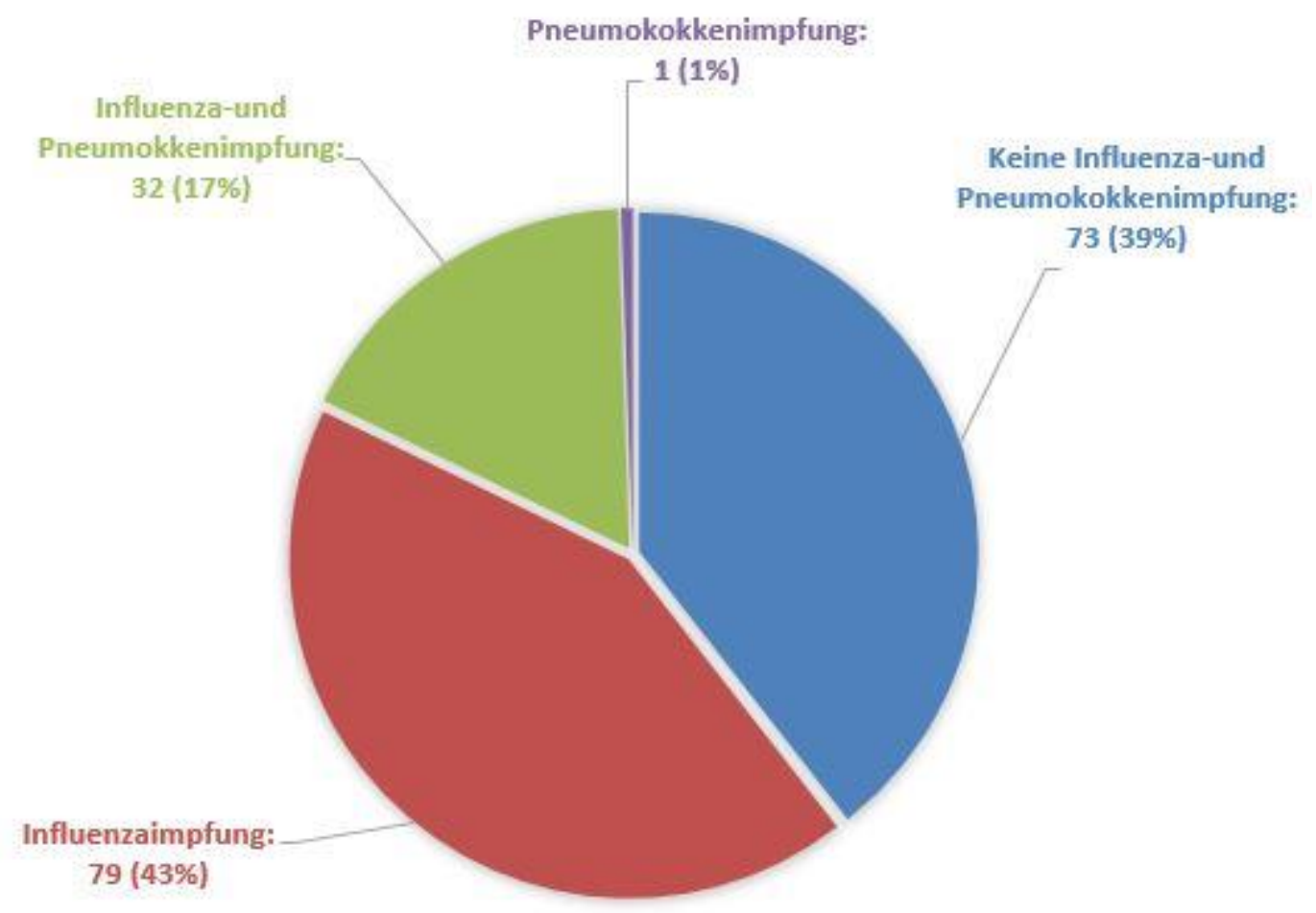

Abbildung 5: Influenza- und Pneumokokkenimpfstatus 
INFLUENZAIMPFSTATUS

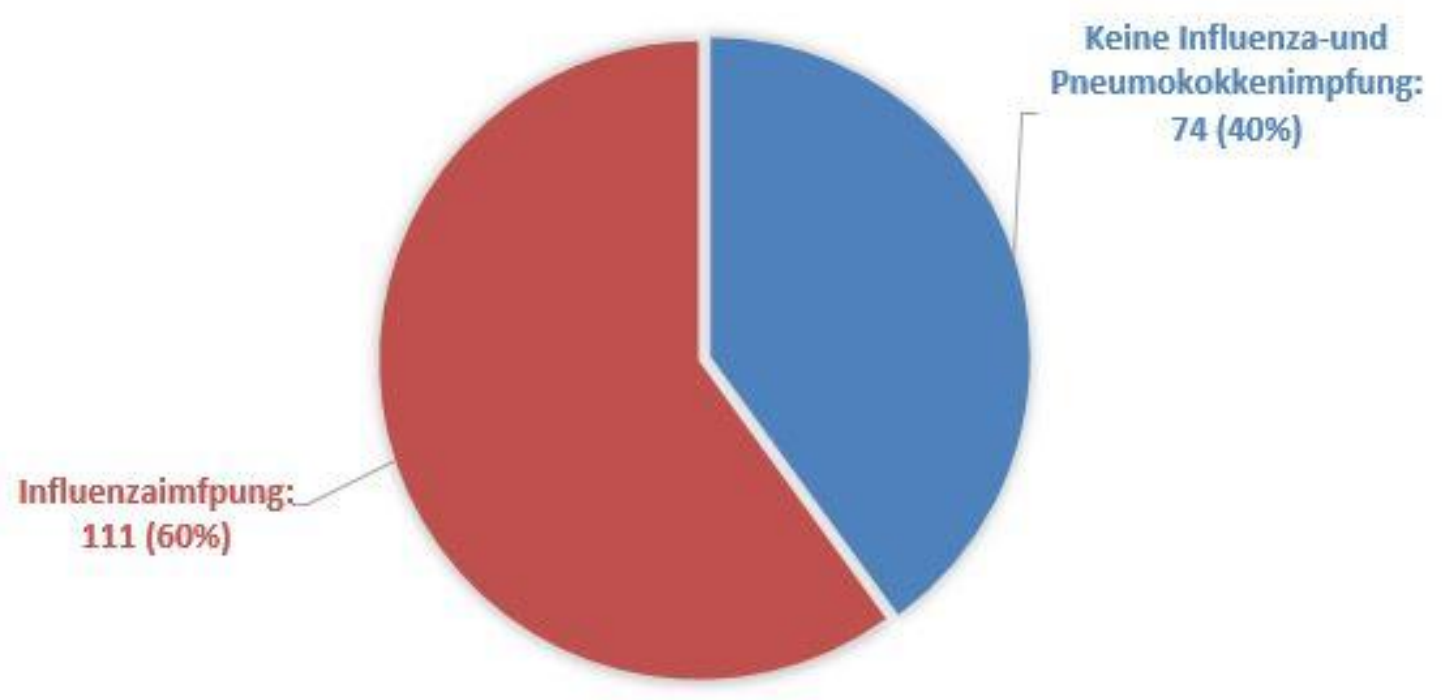

Abbildung 6: Influenzaimpfstatus

\section{PNEUMOKOKKENIMPFSTATUS}

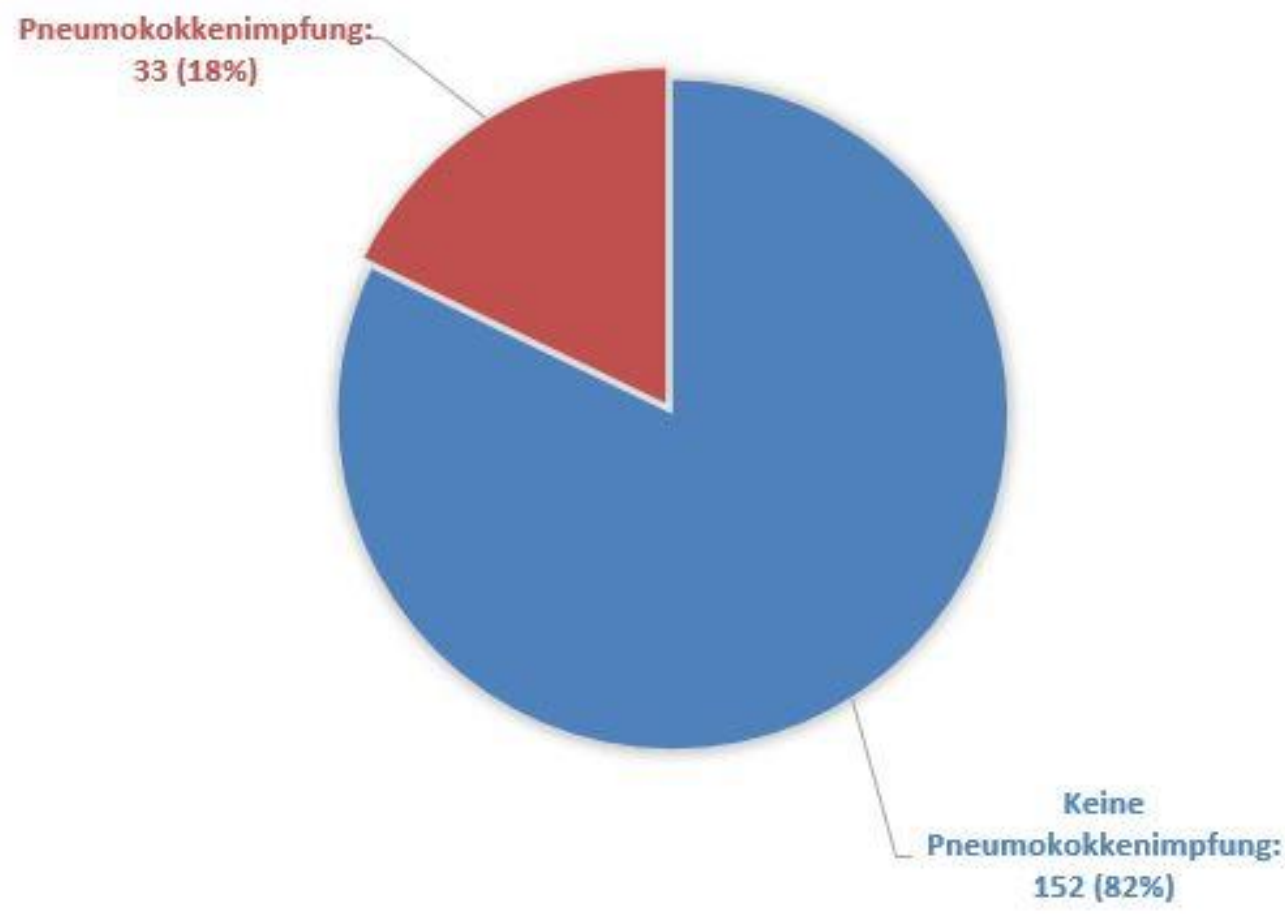

Abbildung 7: Pneumokokkenimpfstatus 


\subsection{Medikation}

\subsubsection{Antibiotika}

Zum Zeitpunkt des Rachenabstriches enthielt die Medikation von 23 Patienten (14,8\%) eine oder mehrere antibiotische Therapien. In dieser Gruppe hatten 14 Patienten schon bis $\mathrm{zu}$ vier Wochen vor Probeentnahme eine oder mehrere antibiotische Behandlungen erhalten. 58 Patienten $(31,3 \%)$ hatten innerhalb der vier Wochen vor Abstreichen der Rachenschleimhaut eine Antibiotikabehandlung als Mono- oder Polytherapie erhalten. Aktuell erhielten sie keine antibiotische Behandlung mehr. Insgesamt hatten somit 81 Patienten (43,8\%) antimikrobielle Therapien in den letzten vier Wochen vor AbstrichEntnahme erhalten. 27 Patienten (14,6\%) erhielten Aminopenicilline, davon 24 in Kombination mit einem B-Lactam-Inhibitor (Tazobactam oder Sulbactam). 14 Patienten (7,6\%) erhielten Cephalosporine der zweiten oder dritten Generation. Acht Patienten (4,3\%) erhielten Carbapeneme. Es wurden 15 Patienten (8,1\%) mit Flourchinolonen therapiert. 10 Patienten (5,4\%) erhielten Trimethoprim und Sulfamethoxazol und 21 Patienten (11,4\%) wurden mit anderen Antibiotika therapiert. 
Tabelle 1: Auflistung der eingenommenen antibiotischen Wirkstoffe vor und während der Probenentnahme

\begin{tabular}{|c|c|c|c|c|}
\hline Wirkstoffgruppe & Wirkstoffe & $\begin{array}{l}\text { Anzahl } \\
\mathrm{n}\end{array}$ & $\begin{array}{l}\text { Prozentual } \\
\% \text { gesamt }\end{array}$ & $\begin{array}{l}\text { Prozentual } \\
\% \text { von } 81\end{array}$ \\
\hline Aminopenicilline & Amoxicillin & 3 & 1,6 & 3,7 \\
\hline \multirow[t]{2}{*}{$\begin{array}{l}\text { Aminopenicilline + } B \text {-Lactam- } \\
\text { Inhibitor }\end{array}$} & $\begin{array}{l}\text { Amoxicillin }+ \\
\text { Sulbactam }\end{array}$ & 9 & 4,9 & 11,1 \\
\hline & $\begin{array}{l}\text { Ampicillin + } \\
\text { Sulbactam }\end{array}$ & 3 & 1,6 & 3,7 \\
\hline \multirow[t]{3}{*}{$\begin{array}{l}\text { Cephalosporine 2./3. } \\
\text { Generation }\end{array}$} & Cefuroxim & 11 & 5,9 & 13,6 \\
\hline & Ceftazidin & 1 & 0,5 & 1,2 \\
\hline & Ceftriaxon & 2 & 1,1 & 2,4 \\
\hline Glykopeptide & Vancomycin & 4 & 2,2 & 4,9 \\
\hline Makrolide & Clarythromycin & 3 & 1,6 & 3,7 \\
\hline Lincosamide & Clindamycin & 1 & 0,5 & 1,2 \\
\hline \multirow[t]{3}{*}{ Fluorochinolone } & Ciprofloxacin & 9 & 4,9 & 11,1 \\
\hline & Levofloxacin & 1 & 0,5 & 1,2 \\
\hline & Moxifloxacin & 5 & 2,7 & 6,2 \\
\hline \multirow[t]{2}{*}{ Carbapeneme } & Imipenem & 4 & 2,2 & 4,9 \\
\hline & Meropenem & 4 & 2,2 & 4,9 \\
\hline Oxazolidinone & Linezolid & 2 & 1,1 & 2,4 \\
\hline $\begin{array}{l}\text { Acylaminopenicilline }+B \text { - } \\
\text { Lactamase-Inhibitor }\end{array}$ & $\begin{array}{c}\text { Piperacillin }+ \\
\text { Tazobactam bzw. } \\
\text { Sulbactam }\end{array}$ & 12 & 6,5 & 14,8 \\
\hline Nitroimidazole & Metronidazol & 9 & 4,9 & 11,1 \\
\hline Nitrofurantoin & & 2 & 1,1 & 2,4 \\
\hline $\begin{array}{l}\text { Trimethoprim }+ \\
\text { Sulfamethoxazol }\end{array}$ & Cotrimoxazol & 10 & 5,4 & 12,3 \\
\hline
\end{tabular}




\section{ANTIBIOTIKABEHANDLUNG}

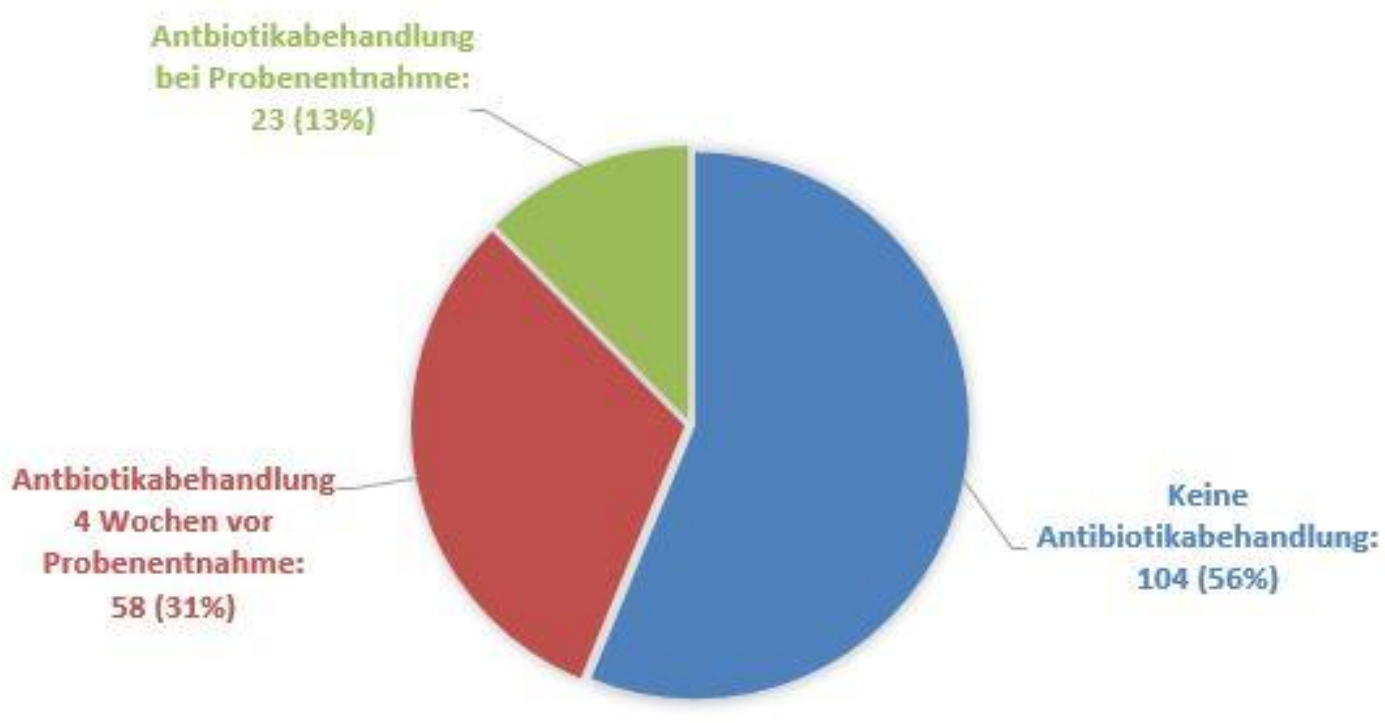

Abbildung 8: Antibiotikabehandlung vor und während der Probenentnahme

\section{ANTIBIOTIKA WIRKSTOFFE}

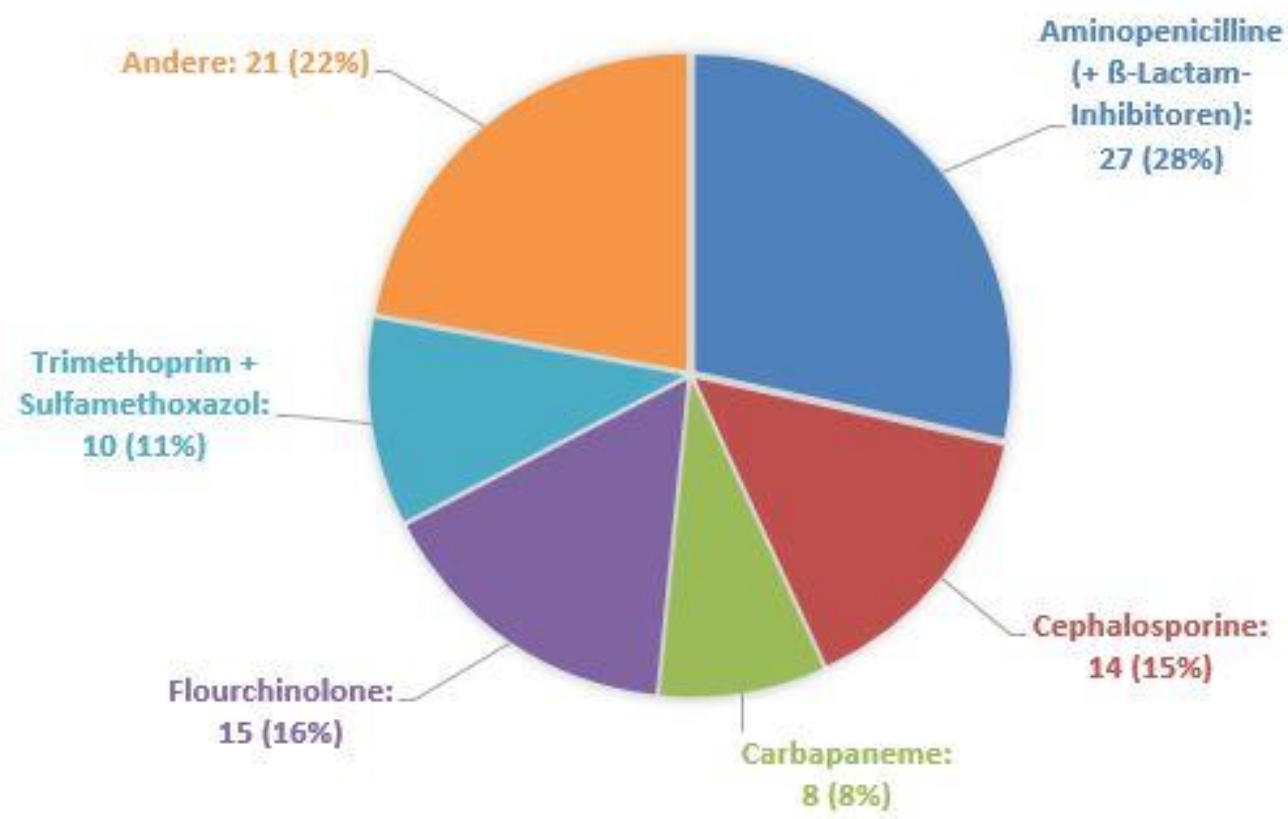

Abbildung 9: Eingenommene antibiotische Substanzgruppen 


\subsubsection{Immunsuppresiva}

23 Patienten (12,4\%) erhielten bei Probenentnahme eine immunsuppresive Therapie. Diese bestand in 21 Fällen aus einer Prednisolontherapie. Ein Patient erhielt den FolsäureAntagonisten Methotrexat. Ein anderer Patient wurde mit Mesalazin (5-Amino-2Hydroxybenzoesäure) behandelt.

\subsubsection{Antiretrovirale Therapie}

Aufgrund einer HIV-Erkrankung erhielt ein Patient eine antiretrovirale Therapie.

\subsubsection{Antazida}

In der Medikation von 54 Patienten (29,1\%) waren Antazida enthalten. 53 Patienten nahmen einen Protonenpumpenhemmer (Pantoprazol, Omeprazol) ein. Ein Patient bekam einen H2-Rezeptorantagonisten. Kein Patient erhielt als Antazidum Sucralfat.

\subsection{Klinische Symptome}

Bei der Befragung bezüglich klinischer auf den Respirationstrakt bezogene Symptome gaben 95 der Patienten (51,4\%) an derzeit unter keinen Beschwerden zu leiden. 23 der Patienten (12,4\%) hatten eine Rhinitis. 22 Patienten (11,9\%) hatten Beschwerden, die unter dem Punkt „Sonstiges“ zusammengefasst wurden. Hier wurden verschiedene Symptome angegeben, wie zum Beispiel Heiserkeit, Nachtschweiß, Ohrenschmerzen und Rückenschmerzen. Diese Symptome waren nicht auf dem Fragebogen aufgeführt und konnten von den Patienten frei angegeben werden. Bei 20 gehörten Xerostomie (10,8\%), bei 18 Dyspnoe (9,7\%), bei 17 Dysphagie (9,2\%), bei 15 Dysgeusie (8,1\%) und bei 13 Husten $(7,2 \%) \mathrm{zu}$ den angegebenen Symptomen. Drei Patienten gaben Mundgeruch $(1,6 \%)$, zwei Halsschmerzen $(1,1 \%)$ und zwei regelmäßiges Niesen $(1,1 \%)$ an. Mehrfachangaben waren zulässig. 


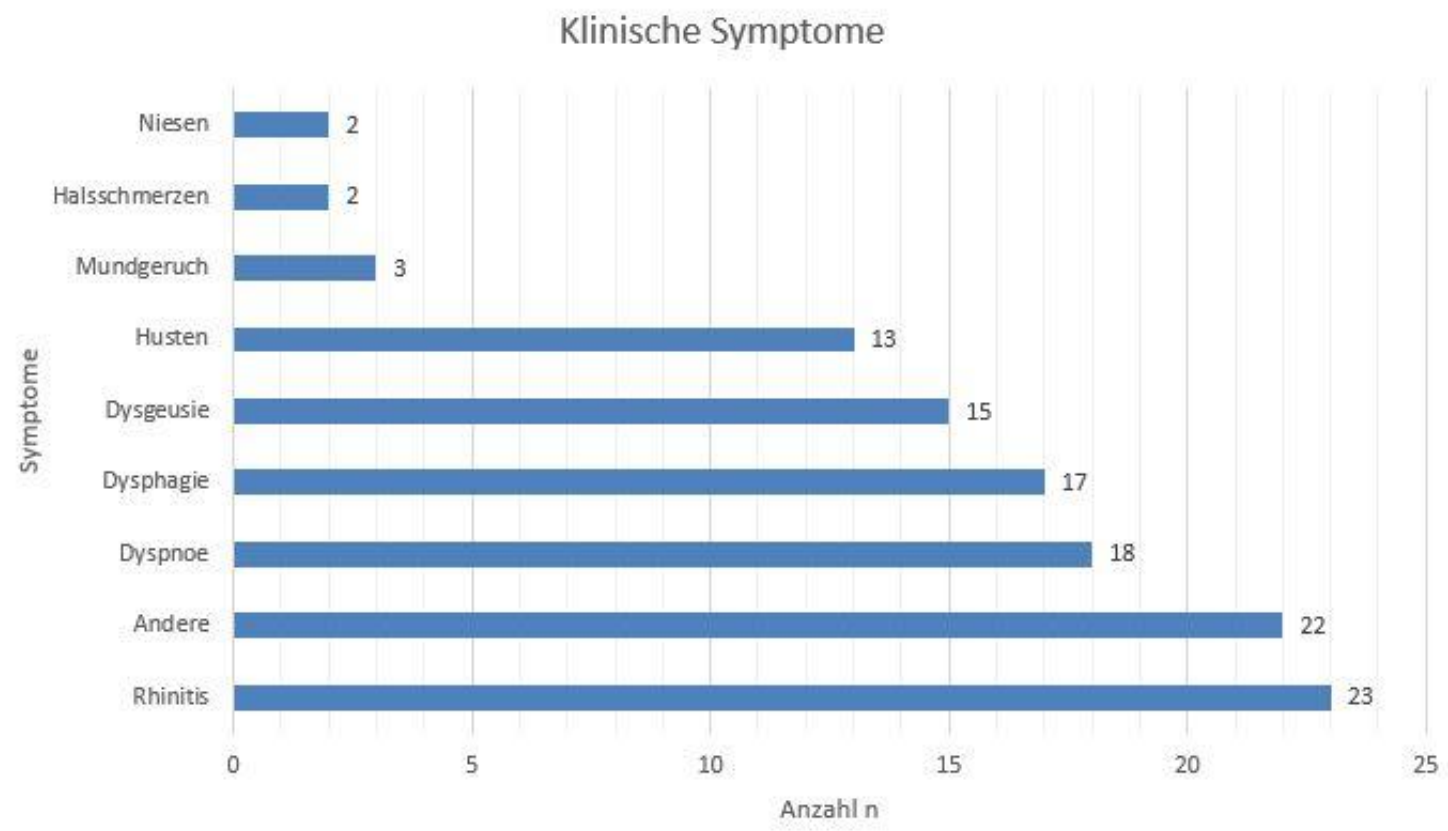

Abbildung 10: Auf den Respirationstrakt bezogene klinische Symptome während der Probenentnahme

\subsection{Barthel-Index}

Um die Pflegebedürftigkeit des Patientenkollektivs in die Studie mit aufzunehmen, wurde der Barthel-Index zur Erfassung grundlegender Alltagsfunktionen hinzugezogen (Mahoney und Barthel 1965). Die Ergebnisse lagen zwischen zehn und 95. Im Durchschnitt betrug der Barthel-Index 50.

\subsection{Klinischer Untersuchungsbefund der Mundhöhle}

Der klinische Untersuchungsbefund der Mundhöhle zeigte bei 21 Patienten (11,4\%) pathologische Veränderungen. Primär waren starke Rötungen der Mundhöhle auffällig $(n=10)$. Außerdem zeigten sich soortypische Beläge $(n=5)$, Schwellungen und Schleimhautveränderungen ( $\mathrm{n}=5)$ und andere Beläge $(\mathrm{n}=2)$.

\subsection{Isoliertes Keimspektrum der Rachenabstriche}

Bei 168 Patienten (90,8\%) waren nach mikrobiologischer Auswertung der Rachenabstriche Keime der normalen Mundflora nachweisbar. Unter den potentiell pathogenen Keimen waren am häufigsten Enterococcus faecalis ( $\mathrm{n}=25 ; 13,5 \%)$, Gram negative Stäbchen $(\mathrm{n}=17$; $9,2 \%)$ und Hefen $(\mathrm{n}=13 ; 7,0 \%)$ vertreten. Vereinzelt wurden Staphylococcus aureus $(\mathrm{n}=4)$, Pseudomonas species $(\mathrm{n}=2)$, Enterococcus speries $(\mathrm{n}=2)$, Staphylococcus epidermidis $(\mathrm{n}=1)$ und Escherichia coli $(\mathrm{n}=1)$ nachgewiesen. Bei keinem Patient konnte eine Besiedlung mit $S$. 
pneumoniae nachgewiesen werden. In 86 Fällen bestand aufgrund der Morphologie der Bakterien ein Verdacht auf S. pneumoniae, der sich aber nach Durchführung des Optochintests in keinem Fall bestätige.

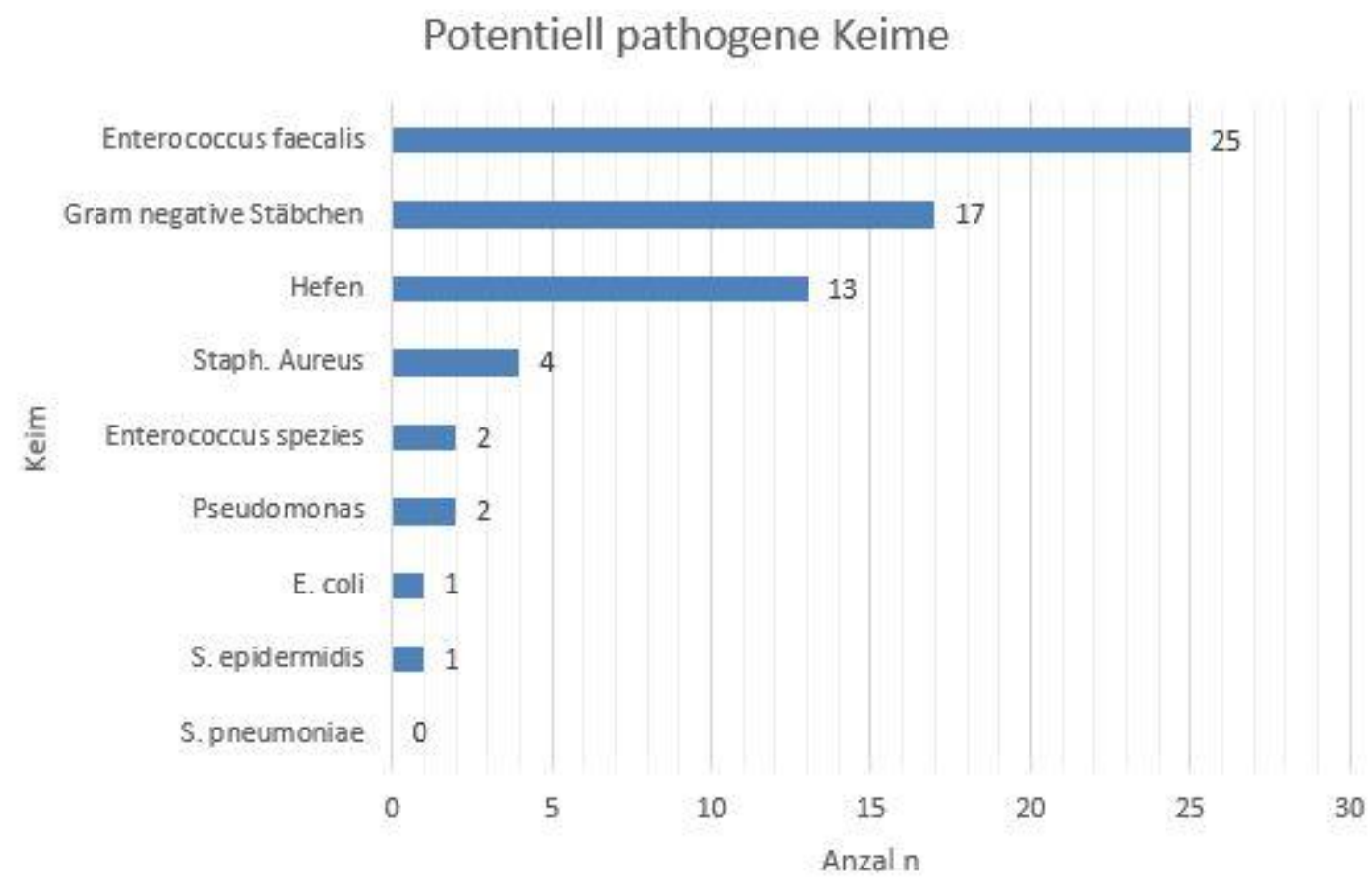

Abbildung 11: Nachgewiesene potentiell pathogene Keime

\subsection{Ergebnisse der Kontrollabstriche}

Bei allen Positivkontrollen wurde S. pneumoniae nachgewiesen. 


\section{Diskussion}

S. pneumoniae ist bei alten Menschen der am häufigsten nachgewiesene Keim bei bakteriellen Infektionskrankheiten. Deshalb sind viele Kliniker, Experten für Infektionskrankheiten eingeschlossen, der Meinung, dass eine hohe Anzahl alter Menschen mit S. pneumoniae besiedelt sein müssen. Da es bisher nur wenige Studien über die Prävalenz der Besiedlung des Respirationstraktes durch S. pneumoniae bei alten Menschen gibt, sollte dies mit Hinblick auf Serotyp- und Antibiotikaresistenzbestimmungen und klinische Relevanz in unserer Studie untersucht werden.

\subsection{Besiedlung des Respirationstraktes durch $S$. pneumoniae bei alten Menschen}

Im Gegensatz zu oben genannter Ansicht weisen unsere Ergebnisse im Einklang mit Ergebnissen anderer Studien auf eine sehr niedrige Besiedlungsrate mit $S$. pneumoniae im Alter. S. pneumoniae konnte in unserer Studie in keiner Probe nachgewiesen werden. In 185 Abstrichen aus dem Rachenraum von geriatrischen Patienten, die aufgrund verschiedener Erkrankungen im Frühjahr 2011 im Geriatrischen Zentrum des Krankenhauses GöttingenWeende hospitalisiert waren, konnten keine S. pneumoniae isoliert werden. Obwohl die Probanden zum größten Teil mulitmorbide waren und aufgrund des fortgeschrittenem Alters oder krankheitsbedingt eine eingeschränkt kompetente Immunantwort besaßen, war keiner mit S. pneumoniae besiedelt. Die Besiedlungsrate von alten Menschen könnte somit wesentlich geringer sein als vorher vermutet.

Vergleichbare Studien erbrachten ähnliche Ergebnisse: In einer australischen Studie wurde nur bei einem von 315 Probanden S. pneumoniae aus nasopharyngealen Proben vor einer Immunisierung mit PPV-23 nachgewiesen. Alle Patienten waren mindestens 60 Jahre alt und wurden in einem Krankenhaus der Maximalversorgung in Sydney behandelt. Nachdem eine Immunisierung bei den 315 Probanden durchgeführt worden war, wurde bei keinem mehr eine Besiedlung mit S. pneumoniae nachgewiesen (Ridda et al. 2010). In Finnland wurden bei 590 gesunden Individuen, die alle mindestens das 65. Lebensjahr erreicht hatten, nasopharyngeale Proben entnommen. Hier lag die Rate einer nasopharyngealen Besiedlung mit S. pneumoniae bei 1,5\% (Palmu et al. 2012). Eine weitere Studie aus Deutschland, die nach unserer durchgeführt wurde, erbrachte ebenfalls eine sehr niedrige Besiedlungsrate. Hierbei wurden bei 541 in Pflegeheimen untergebrachten Probanden 
naso-und oropharyngeale Abstriche entnommen. Das Durchschnittsalter lag bei 84,5 Jahren. Die Prävalenz von S. pneumoniae betrug hier ebenfalls nur 0,8\% (Kwetkat et al. 2018).

Etwas höhere Besiedlungsraten wurden in Israel und Kenya gefunden. In Israel lag diese bei 3,6\% bei den 18 - bis 40 -Jährigen, 3,8\% bei den 41 - bis 65 -Jährigen und 4,6\% bei den über 65-Jährigen (Regev-Yochay et al. 2004). In Kenya waren 6,4\% der Studienteilnehmer zwischen zehn und 85 Jahren besiedelt (Abdullahi et al. 2008). Eine signifikante Zunahme der Besiedlungsraten mit $S$. pneumoniae bei älteren Menschen wurde dagegen in einer Studie in Australien bei Aboriginies nachgewiesen. Hier lag die Prävalenz bei den 16- bis 24Jährigen bei 17,3\%, bei den über 55-Jährigen dagegen bei 38\% (Mackenzie et al. 2010).

Auch wenn die aktuelle Studienlage eine meist niedrige Besiedlungsrate mit $S$. pneumoniae bei alten Menschen aufgezeigt, scheint es hier ebenso wie bei Kindern deutliche geographische Unterschiede zu geben. Warum in bestimmten Regionen alte Menschen nicht und in anderen hingegen deutlich häufiger besiedelt sind, wurde bisher noch nicht belegt.

\subsection{Saisonale Unterschiede der Besiedlungsraten}

Jahreszeitliche Variationen in den Besiedlungraten wurden bereits in verschiedenen Studien beschrieben. Vor allem im Frühjahr fallen die Besiedlungsraten besonders hoch aus. Eine italienische Studie mit 1580 gesunden Kindern im Alter zwischen einem und sieben Jahren zeigte eine größere Besiedlungsrate im Frühling als im Herbst auf (Marchisio et al. 2001). In einer Studie aus Polen lagen die Besiedlungsraten durch $S$. pneumoniae bei Kindern im Herbst bei 37\%, im Winter bei 33,1\% und im Frühling bei 44,4\% (Korona-Glowniak und Malm 2012). In einer weiteren Studie aus den USA wurden die Besiedlungraten von $S$. pneumoniae, Haemophilus influenza und Moraxella catarrbalis bei Kindern, die in Virginia lebten und zwischen 1 und 9 Jahre jung waren, ermittelt. Hier waren die Besiedlungensraten zwar im Winter am höchsten, wobei sich die Besiedlungsraten im Frühling nur gering unterschieden (Hendley et al. 2005). Hof et al. (2013) belegten durch die Auswertung einer Datensammlung von Laborergebnissen aus Deutschland zwischen 2005 und 2010, dass eine Häufung der Pneumokokkensepsis (die Patienten waren zum größten Teil hochbetagt) zwischen Januar und Mai auftrat (Hof et al. 2013). Wir gingen deshalb bei unserem geriatrischen Kollektiv ebenfalls von einer hohen Besiedlungsrate im Frühjahr aus. Da es eines unserer Ziele war so viele Stämme wie möglich zu isolieren, wählten wir somit als Zeitpunkt der Probenentnahmen ebenfalls die Frühlingsmonate. 


\subsection{Antibiotische Therapie}

Ein Grund warum in keiner Probe unserer Studie S. pneumoniae nachgewiesen werden konnte, könnte der hohe Anteil an Studienteilnehmer, die eine antibiotische Behandlung während oder kurze Zeit vor der Probenentnahme erhielten, gewesen sein. Viele der Probanden wurden vor oder während der Studiendurchführung mit einem B-LaktamAntibiotikum therapiert (siehe Tabelle 1). $\mathrm{Da}$ in Deutschland die Prävalenz von penicillinresistenten Pneumokokken immer noch niedrig ist und S. pneumoniae damit hier zu Lande noch sehr gut behandelbar ist, könnte das die Besiedlungsrate deutlich reduziert haben. In Studien, die bei Kindern durchgeführt wurden, erhöhte eine vorausgegangene antibiotische Therapie die Besiedlungsraten (Katsarolis et al. 2009; Korona-Glowniak und Malm 2012). Im Gegensatz dazu war die Prävalenz besiedelter Probanden jedoch niedriger, wenn eine antibiotische Therapie zum Zeitpunkt der Probenentnhame oder sehr kurze Zeit vor dem Abstrich erfolgte (Korona-Glowniak und Malm 2012; Pebody et al. 2009; RegevYochay et al. 2004). Diese Ergebnisse würden somit unsere These einer fehlender Besiedlung aufgrund der breiten Anwendung antimikrobieller Therapien vor und während der Sudiendurchführung bekräftigen. Da aber auch bei den Probanden ohne vorausgegangene antibiotische Therapie keine Besiedlung durch $S$. pneumoniae nachgewiesen wurde, können wir nur vermuten, dass die vorherige Behandlungen mit Antibiotika die Besiedlungsraten reduzieren.

\subsection{Klinische Symptome und Risikofaktoren}

48,6\% unserer Studienteilnehmer gaben Symptome bezüglich des Respirationstraktes an, $12,4 \%$ erhielten eine immunsupprimierende Therapie und 12,4\% nahmen regelmäßig Antazida ein. Da keiner unserer Probanden eine Besiedlung mit S. pneumoniae aufwies, konnten wir keinen Zusammenhang zwischen einer Besiedlung und einer klinischen Symptomatik oder anderen Risikofaktoren herstellen. Bestimmte Risikofaktoren scheinen eine Erkrankung mit Pneumokokken zwar wesentlich zu beeinflussen (Gavazzi und Krause 2002), was durch unsere Studie jedoch nicht belegt werden konnte.

\subsection{Oropharyngeale Probenentnahme und Methodik}

Im Vergleich zu anderen Studien, beschränkte sich diese Studie auf die Entnahme von oropharyngealen Abstrichen um das multimorbide und hochbetagte Patientenkollektiv, soweit möglich, vor weiteren invasiven Eingriffen zu schützen. Im Gegensatz zu Studien bei Kindern, bei denen sich die Entnahme von Proben aus dem Nasopharyngealraum als die sensitivste Methode erwies, schien bei Erwachsenen die Abstrichentnahme aus dem 
Oropharyngealraum die sensitivere Methode zu sein ( Regev-Yochay et al. 2004; Trzciński et al. 2013). In einer Anfang 2018 veröffentlichte Studie aus Deutschland in der sowohl Abstriche aus dem Nasopharyngealraum als auch aus dem Oropharyngealraum von 541 Probanden mit einem Durchschnittsalter von 84,5 Jahren entnommen wurde, wurde eine höhere Anzahl von Pneumokkenbesiedlung in den Abstrichen aus dem Nasopharyngealraum nachgewiesen. Insgesamt war auch bei dieser Studie die Prävalenz der Pneumokkenbesiedlung mit $1,1 \%$ sehr niedrig (zudem wurde $0,3 \%$ davon nach Serotypenbestimmung als S. pseudopneumoniae identifiziert) (Kwetkat et al. 2018). Deshalb gehen wir davon aus, dass wir keine signifikant höhere Besiedlungsrate hätten nachweisen können, wenn wir auch nasopharyngeale Abstriche entnommen hätten. Trotzdem würden wir bei erneuten Studien zu diesem Thema ebenso Abstriche aus dem Nasopharyngealraum entnehmen.

Die Oropharyngealabstriche wurden nach Entnahme innerhalb von vier Stunden in das mikrobiologische Institut transportiert und sofort kultiviert. Bei einem Verdacht auf Pneumokokkenwachstum führten wir zur weiteren Differenzierung einen Optochintest durch. Zur Qualtitätskontrolle wurden Positivkontrollen mit drei verschiedenen Laborstämmen gemacht. Sowohl durch Literaturrecherchen als auch durch eine Qualtätskontrolle haben wir unsere Methotik hinterfragt um eine falsche Minderbesiedlung ausschließen zu können.

\subsection{Molekulare Methoden}

Heutzutage gibt es molekulare Methoden, insbesondere Polymerase-Kettenreaktion (engl. polymerase chain reactions (PCR)), die eine wesentlich höhere Sensitivität aufweisen um auch geringe Besiedlungen durch S. pneumoniae nachzuweisen (Carvalho et al. 2010; Ferreira et al. 2013; Trzciński et al. 2013). Da das Ziel unserer Studie jedoch nicht die alleinige Häufigkeitsbestimmung der Besiedlung durch S. pneumoniae war, sondern zudem die Bestimmung der Serotypen und der Antibiotikaresistenzen, wurden die Proben klassisch kultiviert und keine molekularen Methoden hinzugezogen. Eventuell hätten wir Besiedlungen nachweisen können, wenn wir auch molekulare Methoden genutzt hätten.

\subsection{Ambulant erworbene Pneumonie durch S. pneumoniae}

Auch wenn eine Besiedlung mit S. pneumoniae sowohl in unserer Studie als auch in anderen Studien bei Erwachsenen nicht vorhanden war bzw. sehr niedrig ausfiel, bleibt $S$. pneumoniae der am häufigste nachgewiesene Keim bei ambulant erworbenen Pneumonien. In einer groß angelegten deutschen Studie konnte bei 32\% der Patienten, die aufgrund einer 
ambulant erworbenen Pneumonie stationär behandelt wurden, ein Keim isoliert werden. Bei 40\% war es S. penumoniae (Pletz et al. 2011). Eine andere deutsche Studie wurde im Zeitraum über acht Jahre mit 3087 Patienten durchgeführt. Alle Probanden waren älter als 65 Jahre und ebenfalls aufgrund einer ambulant erworbenen Pneumonie hospitalisiert. 518 davon lebten in einem Pflegeheim. S. pneumoniae war auch bei dieser Studie der am häufigtse vorkommende Keim unter den positiven Proben in beiden Gruppen (ambulant erworbene Pneumonie: 35,9\%; im Pflegeheim erworbene Pneumonie: 32,5\%) (Ewig et al. 2012). Hof et al. (2013) konnten in ihrer Studie aufzeigen, dass vor allem alte Menschen signifikant häufiger an einer Pneumokokkensepsis als der Rest der Bevölkerung erkranken (Hof et al. 2013).

\subsection{Impfung gegen $S$. pneumoniae}

Über die Effektivität des 23-valenten Impstoffes gegen Pneumokokken wird seit Jahren geforscht und disskutiert. Auch wenn es Studienergebnisse gibt, die mit dieser Impfung einen Schutz vor Pneumokokkenpneumonien im Erwachsenenalter nachweisen konnten (Vila-Córcoles et al. 2006), gibt es widerum auch zahlreiche Studien, die keinen signifikanten protektiven Effekt aufzeigen konnten (Assaad et al. 2012; Babouee et al. 2010; Pletz et al. 2008). Ob dies ein Grund für die unzureichende Akzeptanz trotz Empfehlung für eine Pneumokokkenimpfung bei Senioren ist, ist unklar. 2008 ergab eine Umfrage bei 1009 Personen im Alter über 50 Jahre, dass nur 28\% der über 60-Jährigen gegen Pneumokokken geimpft waren (Hutt et al. 2010). Die bevölkerungsrepräsentative Studie zur Gesundheit Erwachsener in Deutschland (DEGS1) ermittelte eine ähnlich Impfrate von 31,4\% bei den 65-bis 79-Jährigen (Poethko-Muller and Schmitz 2013). In unserer Studie fiel der Anteil der geimpften Probanden mit 17,8\% ebenfalls niedrig aus. Auch wenn eine 100\%ige Prävention mit der PPSV-23 keinesfalls erzielt werden kann und eine langanhaltende Immunität nicht nachgewiesen ist (Törling et al. 2003), schützt die Vakzine vor der schweren und lebensbedrohlichen Komplikation einer Sepsis (Mykietiuk et al. 2006).

Seit Einführung der Routineimpfung bei Kindern mit dem 7-valenten Konjugatimpfstoff zu Beginn diesen Jahrhunderts ist die Inzidenz von invasiven Pneumokokkenerkrankungen bei Kindern stark gesunken (Pilishvili et al. 2010). Aber nicht nur die Kinder selbst schützt die Impfung vor Infektionen, auch ein signifikanter Rückgang der invasiven Pneumokokkenerkrankungen bei ungeimpften konnte nachgewiesen werden. Durch den Impfstoff wurde eine Herdenimmunität herbeigeführt. Nicht nur der Geimpfte selbst, 
sondern auch die Umgebung, einschließlich der Risikopopulation, profitieren somit von der Impfung (Duggan 2012; van der Linden et al. 2015).

Allerdings nahm der Anteil an Serotypen, die vor Einführung der Konjugatimpfstoffe nur eine untergeordnete Rolle in der Ursache für invasive Pneumokokkeninfektionen spielten, deutlich zu (Hicks et al. 2007). Durch die Weiterentwicklung des 7-valenten zu einem 13valenten Konjugatimpfstoff wurden fünf weitere stark pathogene Serotypen in die Immunisierung mit aufgenommen. Die durch die Immunisierung abgedeckten Serotypen konnten zwar als Ursache für invasiven Pneumokokkenerkrankungen deutlich gesenkt werden, aber nach Einführung des 13-valenten Konjugatimpfstoffes sind nun wieder andere Serotypen als Erkrankungsursache vermehrt nachweisbar (van der Linden et al. 2015).

In einer großen prospektiven, randomisierten Studie mit insgesamt 84496 Teilnehmern wurde die Wirksamkeit von PCV-13 bei alten Menschen ( $\geq 65$ Jahre) zur Reduktion der Pneumokokken-CAP untersucht. In der CAPITA Studie konnte eine signifikante Reduktion von ambulant erworbenen invasiven und nicht-invasiven PneumokokkenPneumonien durch die Vakzineserotypen nachgewiesen werden. Dabei betrug die Reduktion aller invasiven Pneumokokken-Erkrankungen durch Vakzineserotypen 75\% und die der nicht-invasiven Pneumonieformen 45\%. In der Studie konnte ebenfalls nachgewiesen werden, dass bei der PCV-13, im Gegensatz zur PPSV-23, der Impfeffekt auch nach vier Jahren ohne Anhalt auf einen Wirkungsverlust anhält (Bonten et al. 2015). Nach erfolgter Impfung mit PCV-13 kann zudem eine Booster-Reaktion für eine nachfolgende PPSV-23-Impfung erlangt werden (Jackson et al. 2013). In den USA wird seit 2014 bei allen Personen über 65 Jahre eine PCV-13-Impfung, gefolgt von einer PPSV-23Impfung empfohlen (Kim et al. 2015). In Deutschland hat die STIKO 2018 eine solche Empfehlung noch nicht ausgesprochen (Ständige Impfkommission 2018).

\subsection{Ausblick}

Zusammengefasst war unser Ergebnis mit der fehlenden Besiedlung des Oropharyngealraums mit S. pneumoniae bei einem multimorbiden, hospitalisierten Patientenkollektiv überraschend. Im Einklang mit anderen Studien scheint eine Besiedlung mit S. pneumoniae über einen längeren Zeitraum bei alten Menschen selten zu sein (Kwetkat et al. 2018; Palmu et al. 2012; Ridda et al. 2010). Ausnahmen stellen dabei möglicherweise bestimmte ethnische Gruppen dar. Da eine Besiedlung mit Pneumokokken anscheinend einen protektiven Effekt auf eine erneute Infektion vermittelt (Ferreira et al. 2013), stellt eine chronische Pneumokokkenbesiedlung bei alten Menschen möglicherweise keine 
Ursache für invasive Pneumokokkenerkrankungen dar. Es ist eher davon auszugehen, dass aufgrund der Immunoseneszenz ein Kontakt mit $S$. pneumoniae in ausreichender Bakterienlast, zur sofortigen Erkrankung führt. Da die bisher durchgeführten Studien zur Effektivität der Immunsierung von alten Menschen mit den neuen Konjugatimspfstoffen (Prevenar 13®) einen Rückgang von invasiven Pneumokkenerkrankungen nachweisen konnten, sollte die Einführung einer Routineimpfung mit dem 13-valenten Konjugatimpfstoff gefolgt von einer PPSV-23-Impfung, wie bereits in den USA vorgesehen, auch hier für alte Menschen überdacht werden. In den kommenden Jahren muss zudem ein besonderes Augenmerk auf der Dokumentation der Serotypen, die zu invasiven Erkrankungen führen, liegen um beobachten zu können, inwiefern andere Serotypen die bisherigen pathogenen Stämme ersetzen (van der Linden et al. 2015). Inwieweit es finanziell tragbar sein wird und auch technisch möglich ist, den Konjugatimpfstoff gegebenenfalls um weitere Serotypen zu ergänzen, bleibt derzeit offen. Zudem sollte weiterhin nach Alternativen zur Prävention von Pneumokokkenerkrankungen gesucht werden. In einer experimentellen Studie konnte bei 29 von 70 gesunden Probanden, die zuvor intranasal eine Probe von S. pneumoniae des Serotyp 6B verabreicht bekamen, eine Besiedlung nachgewiesen werden. Nach erneuter intranasalen Verabreichung des Keimes war keine Besiedlung mehr bei den Probanden nachweisbar. Damit bestätigte sich ein protektiver Effekt einer Erstbesiedlung gegen eine spätere Infektion. Das Tragen des Keimes erhöhte sowohl Schleimhaut- als auch SerumIgG Konzentrationen gegen Pneumokokkenproteine und Pneumokokkenpolysaccharide. Zudem verlieh das Serum von besiedelten Probanden Schutz gegen eine ansonsten tödliche Probe mit $S$. pneumoniae in einem Mäuse-Pneumonie-Modell für schwere Pneumokokkenerkrankungen. Die Autoren schlossen daraus, dass die Entwickulung einer Pneumokokken-Schleimhaut-Impfung sowohl das lokale als auch systemische Abwehrsystem aktivieren könnte und somit einen Schutz gegen invasive Erkrankungen und aber auch gegen Besiedlung bieten könnte (Ferreira et al. 2013). 


\section{$5 \quad$ Zusammenfassung}

S. pneumoniae ist der häufigste pathogene Keim, der bei hochbetagten Menschen zu Communitiy aquired pneumonia (CAP) führt. Es ist jedoch wenig über die Häufigkeit der Besiedlung durch S. pneumoniae bei alten Menschen bekannt. Aus diesem Grund wurde eine mögliche Besiedlung des Oropharyngealraumes bei geriatrischen Patienten untersucht.

Die Studie wurde bei hospitalisierten, geriatrischen Patienten im Evangelischen Krankenhaus Göttingen-Weende durchgeführt. Im Zeitraum vom 29. März bis zum 22. Juni 2011 wurden 200 Patienten gebeten, einen Fragebogen zu beantworten und einen Oropharyngealabstrich abzugeben. Bei 15 Patienten war eine Teilnahme an der Studie aufgrund von Teilnahmeablehnung oder starker Demenz nicht möglich. Bei 185 Patienten konnte ein Rachenabstrich gewonnen werden. Die Abstriche wurden auf Blutagar kultiviert. Pneumokokkenverdächtige Kulturen wurden durch einen Optochintest weiter differenziert.

Das Alter der Studienteilnehmer (127 weiblich (68,6\%), 58 männlich $(31,4 \%))$ reichte von 54 bis 101 Jahre (der Median betrug 81 Jahre). 111 Patienten (60,0\%) waren gegen Influenzaviren geimpft, $33(17,8 \%)$ hatten eine Pneumokokkenimpfung erhalten. 58 Patienten $(31,4 \%)$ wurden in den letzten vier Wochen vor Entnahme des Abstrich mit einem oder mehreren Antibiotika behandelt, 23 (12,4\%) erhielten zum Zeitpunkt des Rachenabstrichs eine Antibiose. Immunsupprimierende Medikamente nahmen 23 Patienten (12,4\%) ein, ein Patient wurde antiretroviral behandelt. Bei keinem Rachenabstrich konnte eine Pneumokokkenbesiedlung nachgewiesen werden. Es zeigten sich vor allem Keime der normalen Mundflora.

Bei keinen der 185 Rachenabstriche konnte eine Besiedlung mit S. pneumoniae nachgewiesen werden. Ältere Menschen scheinen, im Gegensatz zu jüngeren Menschen weitaus weniger chronisch mit Pneumokokken besiedelt zu sein als bisher angenommen. Weder das Alter noch andere Einflüsse (Medikation, Komorbidität, klinische Sympotmatik, etc.) scheinen eine chronische Besiedlung bei hochbetagten Menschen zu beeinflussen. Wir vermuten, dass eine chronische Pneumokokkenbesiedlung nicht Ursache invasiver Pneumokokkenerkrankungen bei alten Menschen ist und folgern, dass eine Besiedlung durch S. pneumoniae am ehesten sofort zur Erkrankung und klinischen Symptomatik führt. 
Abdullahi O, Nyiro J, Lewa P, Slack M, Scott JAG (2008): The descriptive epidemiology of Streptococcus pneumoniae and Haemophilus influenzae nasopharyngeal carriage in children and adults in Kilifi District, Kenya. Pediatr Infect Dis J 27, 59-64

Alonso De Velasco E, Verheul AF, Verhoef J, Snippe H (1995): Streptococcus pneumoniae: virulence factors, pathogenesis, and vaccines. Microbiol Rev $\underline{59}, 591-$ 603

Andersson B, Dahmén J, Frejd T, Leffler H, Magnusson G, Noori G, Edén CS (1983): Identification of an active disaccharide unit of a glycoconjugate receptor for pneumococci attaching to human pharyngeal epithelial cells. J Exp Med 158, 559570

Assaad U, El-Masri I, Porhomayon J, El-Solh AA (2012): Pneumonia immunization in older adults: review of vaccine effectiveness and strategies. Clin Interv Aging $\underset{7}{ }$, 453-461

Assefa A, Gelaw B, Shiferaw Y, Tigabu Z (2013): Nasopharyngeal Carriage and Antimicrobial Susceptibility Pattern of Streptococcus Pneumoniae among Pediatric Outpatients at Gondar University Hospital, North West Ethiopia. Pediatr Neonatol $\underline{54}, 315-321$

Austrian R (1999): The Pneumococcus at the Millennium: Not Down, Not Out. J Infect Dis $\underline{179}$, S338-S341

Babouee B, Widmer AF, Battegay PM (2010): Impfungen gegen Pneumokokken und Influenza. Internist $\underline{52}, 265-276$

Bisharat N, Omari H, Lavi I, Raz R (2001): Risk of infection and death among postsplenectomy patients. J Infect $\underline{43}, 182-186$

Bogaert D, Engelen MN, Timmers-Reker AJ, Elzenaar KP, Peerbooms PG, Coutinho RA, de Groot R, Hermans PW (2001): Pneumococcal carriage in children in The Netherlands: a molecular epidemiological study. J Clin Microbiol 39 , 3316-3320 
Bogaert D, van Belkum A, Sluijter M, Luijendijk A, de Groot R, Rümke HC, Verbrugh HA, Hermans PWM (2004a): Colonisation by Streptococcus pneumoniae and Staphylococcus aureus in healthy children. Lancet $\underline{363}, 1871-1872$

Bogaert D, De Groot R, Hermans PWM (2004b): Streptococcus pneumoniae colonisation: the key to pneumococcal disease. Lancet Infect Dis $\underline{4}, 144-154$

Bonten MJM, Huijts SM, Bolkenbaas M, Webber C, Patterson S, Gault S, van Werkhoven CH, van Deursen AMM, Sanders EAM, Verheij TJM, et al. (2015): Polysaccharide conjugate vaccine against pneumococcal pneumonia in adults. N Engl J Med $\underline{372}$, $1114-1125$

Borer A, Meirson H, Peled N, Porat N, Dagan R, Fraser D, Gilad J, Zehavi N, Yagupsky P (2001): Antibiotic-Resistant Pneumococci Carried by Young Children Do Not Appear to Disseminate to Adult Members of a Closed Community. Clin Infect Dis $\underline{33}, 436-444$

Bowen MK, Thiele LC, Stearman BD, Schaub IG (1957): The Optochin sensitivity test: a reliable method for identification of pneumococci. J Lab Clin Med 노, 641-642

Burman LA, Norrby R, Trollfors B (1985): Invasive pneumococcal infections: incidence, predisposing factors, and prognosis. Rev Infect Dis $\underline{7}, 133-142$

Capelastegui A, Zalacain R, Bilbao A, Egurrola M, Iturriaga LAR, Quintana JM, Gomez A, Esteban C, España PP (2014): Pneumococcal pneumonia: differences according to blood culture results. BMC Pulm Med $\underline{14}, 128$

Carvalho M da G, Pimenta FC, Jackson D, Roundtree A, Ahmad Y, Millar EV, O'Brien KL, Whitney CG, Cohen AL, Beall BW (2010): Revisiting Pneumococcal Carriage by Use of Broth Enrichment and PCR Techniques for Enhanced Detection of Carriage and Serotypes. J Clin Microbiol 48, 1611-1618

Christenson B, Sylvan SP, Noreen B (1997): Carriage of multiresistant Streptococcus pneumoniae among children attending day-care centres in the Stockholm area. Scand J Infect Dis $\underline{29}, 555-558$

Chudwin DS, Artrip SG, Korenblit A, Schiffman G, Rao S (1985): Correlation of serum opsonins with in vitro phagocytosis of Streptococcus pneumoniae. Infect Immun $\underline{50}, 213-217$ 
Croney CM, Nahm MH, Juhn SK, Briles DE, Crain MJ (2013): Invasive and Noninvasive Streptococcus pneumoniae Capsule and Surface Protein Diversity following the Use of a Conjugate Vaccine. Clin Vaccine Immunol 20, 1711-1718

Dagan R, Klugman KP (2008): Impact of conjugate pneumococcal vaccines on antibiotic resistance. Lancet Infect Dis $\underline{8}, 785-795$

Duggan ST (2012): Pneumococcal polysaccharide conjugate vaccine (13-valent, adsorbed) [Prevenar 13(®)]: profile report. Paediatr Drugs 14, 67-69

Ekdahl K, Ahlinder I, Hansson HB, Melander E, Mölstad S, Söderström M, Persson K (1997): Duration of Nasopharyngeal Carriage of Penicillin-Resistant Streptococcus pneumoniae: Experiences from the South Swedish Pneumococcal Intervention Project. Clin Infect Dis $\underline{25}, 1113-1117$

Elberse KEM, van der Heide HGJ, Witteveen S, van de Pol I, Schot CS, van der Ende A, Berbers GAM, Schouls LM (2012): Changes in the composition of the pneumococcal population and in IPD incidence in The Netherlands after the implementation of the 7-valent pneumococcal conjugate vaccine. Vaccine $\underline{30}$, $7644-7651$

Ewig S, Birkner N, Strauss R, Schaefer E, Pauletzki J, Bischoff H, Schraeder P, Welte T, Hoeffken G (2009): New perspectives on community-acquired pneumonia in 388406 patients. Results from a nationwide mandatory performance measurement programme in healthcare quality. Thorax $\underline{64}, 1062-1069$

Ewig S, Klapdor B, Pletz MW, Rohde G, Schütte H, Schaberg T, Bauer TT, Welte T, CAPNETZ study group (2012): Nursing-home-acquired pneumonia in Germany: an 8-year prospective multicentre study. Thorax $\underline{67}, 132-138$

Faden H, Duffy L, Wasielewski R, Wolf J, Krystofik D, Tung Y (1997): Relationship between Nasopharyngeal Colonization and the Development of Otitis Media in Children. J Infect Dis $\underline{175}, 1440-1445$

Feikin DR, Klugman KP (2002): Historical Changes in Pneumococcal Serogroup Distribution: Implications for the Era of Pneumococcal Conjugate Vaccines. Clin Infect Dis $\underline{35}, 547-555$ 
Fenoll A, Granizo JJ, Aguilar L, Giménez MJ, Aragoneses-Fenoll L, Hanquet G, Casal J, Tarragó D (2009): Temporal trends of invasive Streptococcus pneumoniae serotypes and antimicrobial resistance patterns in Spain from 1979 to 2007. J Clin Microbiol 47, 1012-1020

Ferrante A, Rowan-Kelly B, Paton JC (1984): Inhibition of in vitro human lymphocyte response by the pneumococcal toxin pneumolysin. Infect Immun $\underline{46}, 585-589$

Ferreira DM, Neill DR, Bangert M, Gritzfeld JF, Green N, Wright AKA, Pennington SH, Moreno LB, Moreno AT, Miyaji EN, et al. (2013): Controlled Human Infection and Rechallenge with Streptococcus pneumoniae Reveals the Protective Efficacy of Carriage in Healthy Adults. Am J Respir Crit Care Med 187, 855-864

Flamaing J, Verhaegen J, Vandeven J, Verbiest N, Peetermans WE (2008). Pneumococcal bacteraemia in Belgium (1994-2004): the pre-conjugate vaccine era. J Antimicrob Chemoth 61, 143-149

Foster D, Knox K, Walker AS, Grittiths DT, Moore H, Haworth E, Peto T, Brueggemann AB, Crook DW, Oxford Invasive Pneumococcal Surveillance Group (2008): Invasive pneumococcal disease: epidemiology in children and adults prior to implementation of the conjugate vaccine in the Oxfordshire region, England. J Med Microbiol 57, 480-487

García-Rodríguez JÁ, Martínez MJF (2002): Dynamics of nasopharyngeal colonization by potential respiratory pathogens. J Antimicrob Chemother $\underline{50}$, 59-74

Gavazzi G, Krause K-H (2002): Ageing and infection. Lancet Infect Dis 2 , 659-666

Gerok W, Huber C, Meinertz T, Zeidler H (Hrsg.): Die Innere Medizin. Referenzwerk für den Facharzt. 11., völlig neu bearb. und erw. Auflage; Schattauer, Stuttgart 2007

Gunnarsson RK, Holm SE, Söderström M (1998): The prevalence of potential pathogenic bacteria in nasopharyngeal samples from healthy children and adults. Scand J Prim Health Care 16, 13-17

Hahn H, Klein P, Vogt K, Hahn-Falke-Kaufmann-Ullmann (Hrsg.): Medizinische Mikrobiologie und Infektiologie: mit 155 Tabellen. 5., vollst. aktualisierte Auflage; Springer, Heidelberg 2005 
Harper C, Newton P (1989): Clinical aspects of pneumonia in the elderly veteran. J Am Geriatr Soc 37, 867-872

Helferty M, Rotondo JL, Martin I, Desai S (2013): The epidemiology of invasive pneumococcal disease in the Canadian North from 1999 to 2010. Int J Circumpolar Health $\underline{72}$, e21606

Hendley JO, Hayden FG, Winther B (2005): Weekly point prevalence of Streptococcus pneumoniae, Hemophilus influenzae and Moraxella catarrhalis in the upper airways of normal young children: effect of respiratory illness and season. APMIS $\underline{113}$, 213-220

Herold G: Innere Medizin 2016. Gerd Herold Verlag, Köln 2016

Herva E, Luotonen J, Timonen M, Sibakov M, Karma P, Mäkelä PH (1980): The effect of polyvalent pneumococcal polysaccharide vaccine on nasopharyngeal and nasal carriage of Streptococcus pneumoniae. Scand J Infect Dis $\underline{12}$, 97-100

Hicks LA, Harrison LH, Flannery B, Hadler JL, Schaffner W, Craig AS, Jackson D, Thomas A, Beall B, Lynfield R, et al. (2007): Incidence of pneumococcal disease due to non-pneumococcal conjugate vaccine (PCV7) serotypes in the United States during the era of widespread PCV7 vaccination, 1998-2004. J Infect Dis 196, 13461354

Hippenstiel S, Witzenrath M, Opitz B, Schütte H, Rosseau S, Suttorp N (2007): Neues zur Pathophysiologie der Pneumonie. Internist $\underline{48}$, 459-467

Hirschtick RE, Glassroth J, Jordan MC, Wilcosky TC, Wallace JM, Kvale PA, Markowitz N, Rosen MJ, Mangura BT, Hopewell PC, Group the PC of HIS (1995): Bacterial Pneumonia in Persons Infected with the Human Immunodeficiency Virus. N Engl $\mathrm{J} \operatorname{Med} \underline{333}, 845-851$

Hof H, Fahr A, Holfelder M, Schwarz R, Oberdorfer K (2013): Schwere Pneumokokkeninfektionen im Alter - impfpräventabel. Z Gerontol Geriatr $\underline{46}$, $160-166$ 
Höffken G, Lorenz J, Kern W, Welte T, Bauer T, Dalhoff K, Dietrich E, Ewig S, Gastmeier P, Grabein B, et al. (2010): Guidelines of the Paul-Ehrlich-Society of Chemotherapy, the German Respiratory Diseases Society, the German Infectious Diseases Society and of the Competence Network CAPNETZ for the Management of Lower Respiratory Tract Infections and Community-acquired Pneumonia. Pneumologie 64, 149-154

Hutt DHJ, Bennerscheidt P, Thiel B, Arand M (2010): Immunseneszenz und Impfungen im höheren Lebensalter. Ein Diskussionsbeitrag. Med Klin 105, 802-807

Imöhl M, Reinert RR, van der Linden M (2010): Temporal Variations among Invasive Pneumococcal Disease Serotypes in Children and Adults in Germany (1992-2008). Int J Microbiol 2010, e874189

Ishida T, Hashimoto T, Arita M, Ito I, Osawa M (1998): Etiology of community-acquired pneumonia in hospitalized patients: a 3 -year prospective study in Japan. Chest $\underline{114}$, 1588-1593

Jackson LA, Gurtman A, van Cleeff M, Frenck RW, Treanor J, Jansen KU, Scott DA, Emini EA, Gruber WC, Schmoele-Thoma B (2013): Influence of initial vaccination with 13-valent pneumococcal conjugate vaccine or 23-valent pneumococcal polysaccharide vaccine on anti-pneumococcal responses following subsequent pneumococcal vaccination in adults 50 years and older. Vaccine $\underline{31}$, 3594-3602

Jacobs MR, Good CE, Beall B, Bajaksouzian S, Windau AR, Whitney CG (2008): Changes in serotypes and antimicrobial susceptibility of invasive Streptococcus pneumoniae strains in Cleveland: a quarter century of experience. J Clin Microbiol $\underline{46}$, 982-990

Jousimies-Somer HR, Savolainen S, Ylikoski JS (1989): Comparison of the nasal bacterial floras in two groups of healthy subjects and in patients with acute maxillary sinusitis. J Clin Microbiol 27, 2736-2743

Katsarolis I, Poulakou G, Analitis A, Matthaiopoulou I, Roilides E, Antachopoulos C, Kafetzis DA, Daikos GL, Vorou R, Koubaniou C, et al. (2009): Risk factors for nasopharyngeal carriage of drug-resistant Streptococcus pneumoniae: data from a nation-wide surveillance study in Greece. BMC Infect Dis $\underline{9}$, e120 
Kellner JD, Vanderkooi OG, MacDonald J, Church DL, Tyrrell GJ, Scheifele DW (2009): Changing Epidemiology of Invasive Pneumococcal Disease in Canada, 1998-2007: Update from the Calgary-Area Streptococcus pneumoniae Research (CASPER) Study. Clin Infect Dis $\underline{49}, 205-212$

Kim DK, Bridges CB, Harriman KH, Centers for Disease Control and Prevention (CDC), Advisory Committee on Immunization Practices (ACIP), ACIP Adult Immunization Work Group (2015): Advisory committee on immunization practices recommended immunization schedule for adults aged 19 years or older--United States, 2015. MMWR Morb Mortal Wkly Rep 64, 91-92

Koivula I, Sten M, Mäkelä PH (1994): Risk factors for pneumonia in the elderly. Am J Med $\underline{96}, 313-320$

Konradsen HB, Kaltoft MS (2002): Invasive pneumococcal infections in Denmark from 1995 to 1999: epidemiology, serotypes, and resistance. Clin Diagn Lab Immunol 9, $358-365$

Korona-Glowniak I, Malm A (2012): Characteristics of Streptococcus pneumoniae strains colonizing upper respiratory tract of healthy preschool children in Poland. ScientificWorldJournal 2012, e732901

Kuikka A, Syrjänen J, Renkonen OV, Valtonen VV (1992): Pneumococcal bacteraemia during a recent decade. J Infect $\underline{24}, 157-168$

Kwetkat A, Pfister W, Pansow D, Pletz MW, Sieber CC, Hoyer H (2018): Naso- und oropharyngeal bacterial carriage in nursing home residents: Impact of multimorbidity and functional impairment. PLoS ONE $\underline{13}$, e0190716

Lee CJ, Banks SD, Li JP (1991): Virulence, immunity, and vaccine related to Streptococcus pneumoniae. Crit Rev Microbiol 18, 89-114

Lipsky BA, Boyko EJ, Inui TS, Koepsell TD (1986): Risk factors for acquiring pneumococcal infections. Arch Intern Med 146, 2179-2185

Lock RA, Paton JC, Hansman D (1988): Purification and immunological characterization of neuraminidase produced by Streptococcus pneumoniae. Microb Pathog $\underline{4}, 33-43$ 
Mackenzie GA, Leach AJ, Carapetis JR, Fisher J, Morris PS (2010): Epidemiology of nasopharyngeal carriage of respiratory bacterial pathogens in children and adults: cross-sectional surveys in a population with high rates of pneumococcal disease. BMC Infect Dis $\underline{10}$, e304

Mahoney FI, Barthel DW (1965): Functional evaluation: The barthel index. Md State Med J $\underline{14}, 61-65$

Marchisio P, Gironi S, Esposito S, Schito GC, Mannelli S, Principi N, Ascanius Project Collaborative Group (2001): Seasonal variations in nasopharyngeal carriage of respiratory pathogens in healthy Italian children attending day-care centres or schools. J Med Microbiol 50, 1095-1099

Musher DM, Alexandraki I, Graviss EA, Yanbeiy N, Eid A, Inderias LA, Phan HM, Solomon E (2000): Bacteremic and nonbacteremic pneumococcal pneumonia. A prospective study. Medicine (Baltimore) $\underline{79}$, 210-221

Musher DM, Rueda AM, Nahm MH, Graviss EA, Rodriguez-Barradas MC (2008): Initial and subsequent response to pneumococcal polysaccharide and protein-conjugate vaccines administered sequentially to adults who have recovered from pneumococcal pneumonia. J Infect Dis $\underline{198}, 1019-1027$

Mykietiuk A, Carratalà J, Domínguez A, Manzur A, Fernández-Sabé N, Dorca J, Tubau F, Manresa F, Gudiol F (2006): Effect of prior pneumococcal vaccination on clinical outcome of hospitalized adults with community-acquired pneumococcal pneumonia. Eur J Clin Microbiol Infect Dis $\underline{25}$, 457-462

Ortqvist A, Hedlund J, Kalin M (2005): Streptococcus pneumoniae : Epidemiology, Risk Factors, and Clinical Features. Semin Respir Crit Care Med 26, 563-574

Palmu AA, Kaijalainen T, Saukkoriipi A, Leinonen M, Kilpi TM (2012): Nasopharyngeal carriage of Streptococcus pneumoniae and pneumococcal urine antigen test in healthy elderly subjects. Scand J Infect Dis $\underline{44}, 433-438$

Pebody RG, Morgan O, Choi Y, George R, Hussain M, Andrews N (2009): Use of antibiotics and risk factors for carriage of Streptococcus pneumoniae: a longitudinal household study in the United Kingdom. Epidemiol Infect 137, 555-561 
Pilishvili T, Lexau C, Farley MM, Hadler J, Harrison LH, Bennett NM, Reingold A, Thomas A, Schaffner W, Craig AS, et al. (2010): Sustained reductions in invasive pneumococcal disease in the era of conjugate vaccine. J Infect Dis 201, 32-41

Pletz MW, Maus U, Krug N, Welte T, Lode H (2008): Pneumococcal vaccines: mechanism of action, impact on epidemiology and adaption of the species. Int J Antimicrob Agents $\underline{32}, 199-206$

Pletz MW, Rohde G, Schütte H, Bals R, von Baum H, Welte T für die CAPNETZStudiengruppe (2011): Epidemiologie und Erreger bei ambulant erworbener Pneumonie (CAP). Dtsch med Wochenschr 136, 775-780

Poethko-Muller C, Schmitz R (2013): Impfstatus von Erwachsenen in Deutschland: Ergebnisse der Studie zur Gesundheit Erwachsener in Deutschland (DEGS1). Bundesgesundheitsblatt Gesundheitsforschung Gesundheitsschutz $\underline{56}$, 845-857

Raymond J, Thomas IL, Moulin F, Commeau A, Gendrel D, Berche P (2000): Sequential Colonization by Streptococcus pneumoniae of Healthy Children Living in an Orphanage. J Infect Dis 181, 1983-1988

Regev-Yochay G, Raz M, Dagan R, Porat N, Shainberg B, Pinco E, Keller N, Rubinstein E (2004): Nasopharyngeal Carriage of Streptococcus pneumoniae by Adults and Children in Community and Family Settings. Clin Infect Dis $\underline{38}$, 632-639

Reinert RR (2009): The antimicrobial resistance profile of Streptococcus pneumoniae. Clin Microbiol Infect 15 Suppl 3, 7-11

Ridda I, Macintyre CR, Lindley R, McIntyre PB, Brown M, Oftadeh S, Sullivan J, Gilbert GL (2010): Lack of pneumococcal carriage in the hospitalised elderly. Vaccine $\underline{28}$, 3902-3904

Riquelme R, Torres A, El-Ebiary M, Mensa J, Estruch R, Ruiz M, Angrill J, Soler N (1997): Community-acquired Pneumonia in the Elderly. Am J Respir Crit Care Med 156, 1908-1914

Robbins JB, Austrian R, Lee CJ, Rastogi SC, Schiffman G, Henrichsen J, Mäkelä PH, Broome CV, Facklam RR, Tiesjema RH (1983): Considerations for formulating the second-generation pneumococcal capsular polysaccharide vaccine with emphasis on the cross-reactive types within groups. J Infect Dis 148, 1136-1159 
Rubins JB, Duane PG, Charboneau D, Janoff EN (1992): Toxicity of pneumolysin to pulmonary endothelial cells in vitro. Infect Immun $\underline{60}, 1740-1746$

Rückinger S, van der Linden M, Reinert RR, von Kries R, Burckhardt F, Siedler A (2009): Reduction in the incidence of invasive pneumococcal disease after general vaccination with 7 -valent pneumococcal conjugate vaccine in Germany. Vaccine 27, 4136-4141

Ruiz-González A, Falguera M, Nogués A, Rubio-Caballero M (1999): Is Streptococcus pneumoniae the leading cause of pneumonia of unknown etiology? A microbiologic study of lung aspirates in consecutive patients with communityacquired pneumonia. Am J Med 106, 385-390

Sankilampi U, Herva E, Haikala R, Liimatainen O, Renkonen OV, Leinonen M (1997): Epidemiology of invasive Streptococcus pneumoniae infections in adults in Finland. Epidemiol Infect $\underline{118}, 7-15$

Schnoor M, Klante T, Beckmann M, Robra BP, Welte T, Raspe H, Schäfer T, CAPNETZ Study Group (2007): Risk factors for community-acquired pneumonia in German adults: the impact of children in the household. Epidemiol Infect 135, 1389-1397

Scott J A, Hall AJ, Dagan R, Dixon JMS, Eykyn SJ, Fenoll A, Hortal M, Jetté LP, Jorgensen JH, Lamothe F, et al. (1996): Serogroup-Specific Epidemiology of Streptococcus pneumoniae: Associations with Age, Sex, and Geography in 7,000 Episodes of Invasive Disease. Clin Infect Dis 22, 973-981

Ständige Impfkommission (2018): Empfehlungen der Ständigen Impfkommission (STIKO) am Robert Koch-Institut. Epid Bull 34, 335-382

St Sauver J, Marrs CF, Foxman B, Somsel P, Madera R, Gilsdorf JR (2000): Risk factors for otitis media and carriage of multiple strains of Haemophilus influenzae and Streptococcus pneumoniae. Emerg Infect Dis $\underline{6}, 622-630$

Syrjänen RK, Kilpi TM, Kaijalainen TH, Herva EE, Takala AK (2001): Nasopharyngeal carriage of Streptococcus pneumoniae in Finnish children younger than 2 years old. J Infect Dis $\underline{184}, 451-459$ 
Törling J, Hedlund J, Konradsen HB, Ortqvist A (2003): Revaccination with the 23-valent pneumococcal polysaccharide vaccine in middle-aged and elderly persons previously treated for pneumonia. Vaccine 22, 96-103

Trzciński K, Bogaert D, Wyllie A, Chu MLJN, van der Ende A, Bruin JP, van den Dobbelsteen G, Veenhoven RH, Sanders EAM (2013): Superiority of Trans-Oral over Trans-Nasal Sampling in Detecting Streptococcus pneumoniae Colonization in Adults. PLoS One $\underline{8}$, e60520

van de Beek D, de Gans J, Spanjaard L, Weisfelt M, Reitsma JB, Vermeulen M (2004): Clinical Features and Prognostic Factors in Adults with Bacterial Meningitis. N Engl J Med 351, 1849-1859

van der Linden M, Falkenhorst G, Perniciaro S, Imöhl M (2015): Effects of Infant Pneumococcal Conjugate Vaccination on Serotype Distribution in Invasive Pneumococcal Disease among Children and Adults in Germany. PLoS One $\underline{10}$, $\mathrm{e} 0131494$

Varon E, Levy C, Rocque FDL, Boucherat M, Deforche D, Podglajen I, Navel M, Cohen R (2000): Impact of Antimicrobial Therapy on Nasopharyngeal Carriage of Streptococcus pneumoniae, Haemophilus influenzae, and Branhamella catarrhalis in Children with Respiratory Tract Infections. Clin Infect Dis $\underline{31}$, 477-481

Venkatesan P, Gladman J, Macfarlane JT, Barer D, Berman P, Kinnear W, Finch RG (1990): A hospital study of community acquired pneumonia in the elderly. Thorax $\underline{45}, 254-258$

Vila-Córcoles A, Ochoa-Gondar O, Hospital I, Ansa X, Vilanova A, Rodríguez T, Llor C, EVAN Study Group (2006): Protective effects of the 23-valent pneumococcal polysaccharide vaccine in the elderly population: the EVAN-65 study. Clin Infect Dis $\underline{43}, 860-868$

Watanakunakorn C, Bailey TA (1997): Adult bacteremic pneumococcal pneumonia in a community teaching hospital, 1992-1996. A detailed analysis of 108 cases. Arch Intern Med 157, 1965-1971 
Whitney CG, Farley MM, Hadler J, Harrison LH, Bennett NM, Lynfield R, Reingold A, Cieslak PR, Pilishvili T, Jackson D, et al. (2003): Decline in invasive pneumococcal disease after the introduction of protein-polysaccharide conjugate vaccine. $\mathrm{N}$ Engl J Med $\underline{348}, 1737-1746$

Yoshikawa TT, Marrie TJ (2000): Community-Acquired Pneumonia in the Elderly. Clin Infect Dis $\underline{31}, 1066-1078$

Yu VL, Chiou CCC, Feldman C, Ortqvist A, Rello J, Morris AJ, Baddour LM, Luna CM, Snydman DR, Ip M, et al. (2003): An International Prospective Study of Pneumococcal Bacteremia: Correlation with In Vitro Resistance, Antibiotics Administered, and Clinical Outcome. Clin Infect Dis $\underline{37}, 230-237$

Zysk G, Schneider-Wald BK, Hwang JH, Bejo L, Kim KS, Mitchell TJ, Hakenbeck R, Heinz H-P (2001): Pneumolysin Is the Main Inducer of Cytotoxicity to Brain Microvascular Endothelial Cells Caused by Streptococcus pneumoniae. Infect Immun $\underline{69}, 845-852$ 
$7 \quad$ Anhang

Befundbogennr:

Datum:

レレは

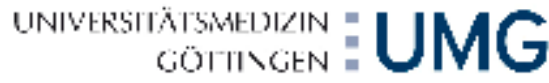
$\underset{\text { Tw }}{\llcorner} \mid$ Monat

\section{Befunderhebungsbogen}

Besiedlung des Respirationstrakts mit potentiell pathogenen Bakterien in einer geriatrischen Klinik und in Pflegeeinrichtungen

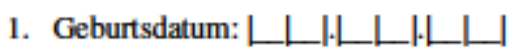

Geschlecht: $\square$ weiblich $\square$ männlich

Tag Monat Jahr

Geschlecht $\square$ weiblich $\square$ mannlich

2. Hauptdiagnose:

Nebendiagnosen:

Diabetes mellitus / Typ/ Behandlungsform:

3. Ernahhrung:

$\square$ oral (Kostform:

) $\square$ enteral (Sonde)

parenteral

4. Vorbehandlungen mit Auswirkungen auf den derzeitigen Gesundheitszustand:

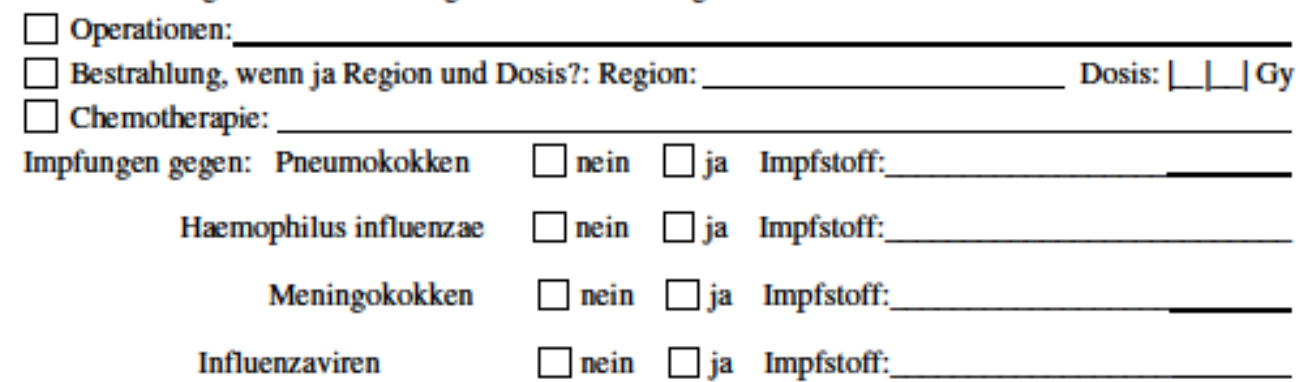

Andere Therapiemaßnahmen:

5. Aktuelle Medikation:

Antibiotika:

$\square$ nein $\square$ ja

Immunsupressiva: $\square$ nein $\square$ ja; Substanzgruppe:

Antimykotika: $\square$ nein $\square$ ja

Medikamente mit Auswirkungen auf den Magensaft-pH: $\quad \square$ nein $\quad \square$ ja

Befunderhebungsbogen Besiedlung des Respirationstrakts mit potentiell pathogenen Bakterien in einer geriatrischen Klinik und in Pflegeeinrichtungen 
Befundbogennr:

Datum:

Medikamente mit Auswirkungen auf den Speichelfluss: $\quad \square$ nein $\quad \square$ ja

Nasensalbe: $\square$ nein $\square$ ja; wenn ja, welche?

Sonstige Medikation:

6. Symptomatik:

$\square$ Keine Beschwerden $\square$ Xerostomie $\square$ Zahnschmerzen $\square$ Mundgeruch
$\square$ Halsschmerzen $\quad \square$ Dysgeusie $\square$ Dysphagie $\square$ Husten
$\square$ Luftnot $\square$ Verstopfte Nase $\square$ Niesen
$\square$ Sonstiges
$\square$ Patient ist nicht befragbar: Grund:

7. Allgemeinzustand und Pflegebedarf ADL

Kamofsky Performace Score __Ll

Pflegestufe $0 \square \quad 1 \square \quad 2 \square \quad 3 \square$

8. Mundhygiene

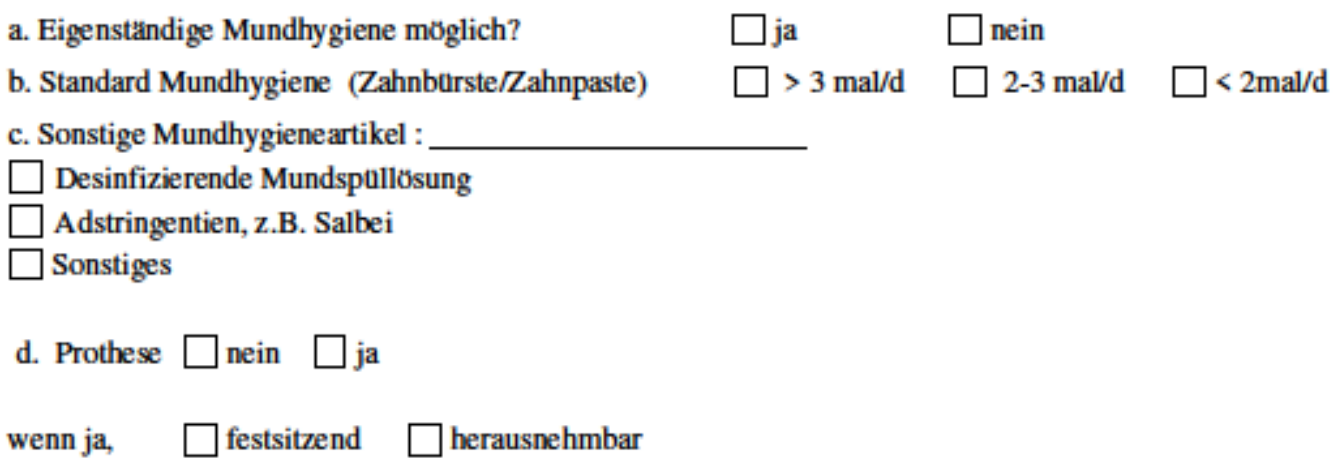
wenn ja, Art der Prothesenhygiene: 
Befundbogennr:

Datum:

$$
\underset{\text { Tæz }}{L} \mid \cdot \underset{\text { Monat }}{L} \cdot \cdot \underbrace{}_{\text {Jahr }}
$$

9. Klinischer Untersuchungsbefund Mundhöhle

$\square$ normal $\square$ gerotet $\quad \square$ geschwollen $\quad \square$ soortypische Belege
$\square$ anderweitige Belege $\quad \square$ Schleimhautveränderungen
$\square$ Ulcus $\quad \square$ Blutung akut $\quad \square$ Aphte

$\square$ Sonstige relevante Befunde der Mundhöhle:

Speichelsekretion $\square$ normal $\square$ reduziert $\square$ vermehrt

12. Verdauung/ Ausscheidungen

Durchfall in den letzten 4 Wochen: $\square$ nein $\square$ ja

Wenn ja, wann? $\square$ aktuell $\square$ vor ca. 3 Tagen $\square$ vor 3-7 Tagen $\square$ vor 7 -14 Tagen $\square$ > 14 Tage

Wenn ja, Haufigkeit / Tag:

13. Haut

a. Auffalligkeiten im Abstrichareal:

$\square$ keine $\square$ Rötung $\square$ schwellung $\square$ offene Wunde $\square$ schuppen $\square$ Sonstige:

b. Sonstige Auffalligkeiten:

$\square$ keine $\square$ Rootung $\square$ schwellung $\square$ offene Wunde $\square$ schuppen $\square$ sonstige: 


\title{
Absence of Streptococcus pneumoniae in pharyngeal swabs of geriatric inpatients
}

\author{
NINA JOMRICH ${ }^{1,2}$, SILVIA KELLNER ${ }^{3}$, MARIJA DJUKIC $^{1,2}$, HELMUT EIFFERT $^{3}$ \& \\ ROLAND NAU ${ }^{1,2}$
}

From the ${ }^{1}$ Department of Geriatrics, Evangelisches Krankenhaus Göttingen-Weende, Göttingen, Germany, and Institutes of ${ }^{2}$ Neuropathology and ${ }^{3}$ Medical Microbiology, University Medicine Göttingen, Göttingen, Germany

\begin{abstract}
Colonization of the pharynx by Streptococcus pneumoniae was studied in 185 in-hospital geriatric patients (median age 81 years) from 29 March 2011 to 22 June 2011 . Swabs were plated on blood agar plates. Colonies with a morphology suggesting $S$. pneumoniae were further analyzed. Surprisingly, pneumococci were not found in any of the samples. Pneumococci chronically colonizing the pharynx of elderly people may be much rarer than previously thought and probably are not the source of pneumococcal pneumonia in old age.
\end{abstract}

Keywords: Colonization, geriatrics, pharyngeal swab, Streptococcus pneumoniae

\section{Introduction}

Streptococcus pneumoniae continues to be one of the most abundant pathogens in humans. It is a major cause of acute otitis media, sinusitis, pneumonia, bacteremia and meningitis throughout the world. In particular, it is the most frequent bacterium causing community-acquired pneumonia and bacterial meningitis in adults, and severe pneumococcal infections are frequently associated with septicemia. The very old, the youngest and immunocompromised people are at a particularly high risk of invasive pneumococcal infections [1-3]. Strategies to prevent pneumococcal pneumonia include vaccination against $S$. pneumoniae and influenza. For the assessment of the efficacy of available vaccines in elderly people and for future improvements in vaccines, it is important to know which serotypes causing colonization and infections in elderly people are covered by available vaccines, and which serotypes frequently are resistant to penicillin, macrolides and tetracyclines. For this reason, our study aimed to isolate pneumococci colonizing in-hospital geriatric patients, characterizing their serotypes and comparing these findings with patterns of serotypes isolated from younger people. When we planned this study, in accordance with many experts with whom we discussed the project, we estimated the rate of pharyngeal colonization by pneumococci to be high as a consequence of multimorbidity and age-, drug- or disease-related impairments of the immune defenses.

\section{Materials and methods}

Between 29 March 2011 and 22 June 2011, 200 hospitalized patients treated at the Department of Geriatrics,Evangelisches Krankenhaus Göttingen-Weende, were asked to participate in this study. Evangelisches Krankenhaus Göttingen-Weende is a primary hospital with 448 beds in the rural area of Lower Saxony, serving a population of approximately $250000(117000$ living in the city of Göttingen). The Geriatric Centre comprises 90 beds.

Written informed consent was required from all participants. Non-demented and non-confused inpatients

Correspondence: Prof. Dr Roland Nau, Department of Geriatrics, Evangelisches Krankerhaus Götringen-IWeende, and Institute of Neuroparhology, University Medicine Görtingen, An der Lutter 24, D-37075 Göttingen, Germany. Tel: +49551 5034 1560. Fax: +49531 5034 1562. E-mail: rnau@gwdg.de

(Received 20 September 2014; actepted 5 faniary 2015)

ISSN $2374-4235$ print/ISSN $2374-4243$ online 02015 Informa Healchcare DOI: $10.3109 / 00365548.2015 .1007476$ 
were asked to participate on the clinical rounds of the Head of the Department (RN), and were informed by $\mathrm{NJ}$ and $M D$ regarding the aims of the study and protection of privacy. We estimated the rate of multimorbid geriatric patients colonized by pneumococci to be approximately $20 \%$. Since we planned to collect $30-40$ strains, the number of 200 patients was chosen. Once written informed consent had been obtained, a questionnaire was conducted with the patient by NJ (see Supplementary Appendix to be found online at http://www.informahealthcare.com/ doi/abs/10.3109/00365548.2015.1007476), and data including diagnoses, medication and the Barthel Activity of Daily Living (ADL) Index [4] as a measure of the patient's functional status were extracted from the medical records.

Specimens were collected by NJ by moving a cotton swab over both tonsils and across the rear wall of the pharynx. All pharyngeal swabs were placed in a sterile polypropylene tube containing Amies agar gel (Transystem $^{\circledR}$; Hain Lifescience, Nehren, Germany) and transported rapidly to the Institute of Medical Microbiology, University Medicine Göttingen, Germany. They were plated on chocolate agar (heat blood agar) and Columbia sheep blood agar plates within $4 \mathrm{~h}$ of sample collection. Plates were incubated at $35-37^{\circ} \mathrm{C}$ in room air supplemented with $5 \%$ carbon dioxide for 48 $\mathrm{h}$. They were read at 24 and $48 \mathrm{~h}$. Colonies with a morphology suggesting $S$. pneumoniae were further analyzed by the Optochin test [5]: colonies were plated again on Columbia sheep agar plates together with disks containing $5 \mu \mathrm{g}$ Optochin (ethylhydrocuprein hydrochloride). As positive controls, swabs were spiked with laboratory strains of S. pneumoniae (D39, R6 and the serotype 3 strain previously used in experimental rabbits, e.g. [6]). Aliquots of these strains were kept at $-80^{\circ} \mathrm{C}$ in $0.9 \%$ $\mathrm{NaCl}$, then thawed, and $10 \mu \mathrm{l}$ was pipetted on to the cotton swabs, which were then processed in the same way as the swabs obtained from the patients.

Statistical comparisons were performed by Fisher's exact test followed by Bonferroni correction for repeated testing (cultured isolates versus antibiotic pretreatment) or by the Mann-Whitney $U$ test (ADL Index versus vaccination status), and $p$ values of 0.05 or less were considered statistically significant. The study was approved by the Ethics Committee, University Medicine Göttingen, and performed in accordance with the ethical standards laid down in the Declaration of Helsinki and subsequent amendments by the World Medical Assembly.

\section{Results}

Fifteen patients did not consent to the pharyngeal swab; therefore, in total, 185 participants were included in the study (127 female, 58 male). The age of the participants ranged from 54 to 101 years (median 81 years) and the majority was multimorbid. The ADL Index ranged from 10 to 95 (median 50). The primary causes of admission to our department are shown in Table $\mathrm{I}$.

Of the 185 patients, $111(60.0 \%)$ had been vaccinated against influenza at least once, and 33 $(17.8 \%)$ against $S$. pneumoniae with the 23 -valent polysaccharide vaccine. Thirty-two patients (17.3\%) had been vaccinated against influenza and pneumococci, and one patient had received the pneumococcal vaccine only. The ADL Index of vaccinated patients (median 60, 25th-75th percentile 40-70) was slightly higher than that of non-vaccinated patients (median 45,25 th-75th percentile $35-55$ ) ( $p=0.02, U$ test).

Fifty-eight patients $(31.4 \%)$ had received antibiotics in the 4 weeks prior to the study, but were not taking antibiotics at the time of swab collection. Twenty-three patients $(12.4 \%)$ were receiving antibiotics at the time of sampling (Table I). At the time of sampling, 23 patients were being treated systemically with drugs with immunosuppressive properties (21 prednisolone, one methotrexate, one mesalazine); 53 patients were taking proton-pump inhibitors and one was taking an antihistamine $\mathrm{H}_{2}$-blocker. Thirty-nine patients had diabetes mellitus.

In 168 patients $(90.8 \%)$, the cultures of pharyngeal swabs grew bacteria physiological to the oral cavity. Among potentially pathogenic microorganisms, swab cultures most frequently grew Enterococcus faecalis $(n=25 ; 13.5 \%)$, Gram-negative aerobic rods $(n=17 ; 9.2 \%$; Pseudomonas spp. not included) and yeasts $(n=13 ; 7.0 \%)$. All potentially pathogenic organisms are listed in Figure 1. Streptococcus pneumoniae was not found in any of the cultures. In 86 cases, the morphology of some colonies suggested $S$. pneumoniae, but the Optochin test was negative in all of these cases. Conversely, pneumococci were detected in all positive control swabs spiked with different laboratory strains of $S$. pneumoniae. Gramnegative aerobic bacteria were cultured from the pharyngeal swabs of $10.8 \%$ of the patients and yeasts were cultured from $7.0 \%$. We did not find substantially increased numbers of Gram-negative bacteria or yeasts in patients treated with antibiotics during the 4 weeks prior to the study or in patients receiving antibiotics at the time of sampling.

\section{Discussion}

Many clinicians, including infectious disease experts, are of the opinion that a high proportion of elderly people must be colonized with $S$. pneumoniae, because $S$. pneumoniae is the most frequent pathogen of bacterial pneumonia in old age. Conversely, limited 
Table I. Clinical data of the patients studied $(N=185)$.

\begin{tabular}{|c|c|}
\hline Patients' characteristics & $\begin{array}{c}\text { No. of } \\
\text { patients (\%) }\end{array}$ \\
\hline Female & $127(68.6)$ \\
\hline Male & $58(31.4)$ \\
\hline \multicolumn{2}{|l|}{ Primary cause of admission } \\
\hline Bone and joint surgery ( 32 patients elective, 54 patients emergency surgery) & $86(46.4)$ \\
\hline Abdominal surgery & $15(8.1)$ \\
\hline Diseases of the nervous system & $36(19.5)$ \\
\hline Chronic lung diseases & $8(4.3)$ \\
\hline Pneumonia & $9(4.9)$ \\
\hline Cardiac failure & $10(5.4)$ \\
\hline Malignant diseases & $3(1.6)$ \\
\hline Hepatic failure & $2(1.1)$ \\
\hline Renal failure & $2(1.1)$ \\
\hline Unexplained detcrioration & $13(7.0)$ \\
\hline Previous influenza vaccination uptake & $111(60.0)$ \\
\hline Previous Streptococeus pneumoniae vaccination uptake & $33(17.8)$ \\
\hline Antibiotic treatment & $81(43.8)$ \\
\hline During sampling & $23(12.4)$ \\
\hline In the last 4 weeks before sampling & $58(31.4)$ \\
\hline \multicolumn{2}{|l|}{ Antibiotic compounds administere $\mathrm{d}^{\mathrm{a}}$} \\
\hline Penicillins $(+\beta$-lactamase inhibitors) & $27(14.6)$ \\
\hline Cephalosporins & $14(7.6)$ \\
\hline Carbapenems & $8(4.3)$ \\
\hline Fluoroquinolones & $15(8.1)$ \\
\hline Trimethoprim + sulfamethoxazole & $10(5.4)$ \\
\hline Others & $21(11.4)$ \\
\hline Immunosuppressive agents (prednisolone, methotrexate, mesalazine) & $23(12.4)$ \\
\hline Proton pump inhibitors & $53(28.6)$ \\
\hline Histaminergic $\mathrm{H}_{2}$-blocker & $1(0.5)$ \\
\hline Diabetes mellitus & $39(21.1)$ \\
\hline Patients with clinical symptoms related to the respiratory tract ${ }^{b}$ & $90(48.6)$ \\
\hline Rhinitis & $23(12.4)$ \\
\hline Xerostomia & $20(10.8)$ \\
\hline Dyspnea & $18(9.7)$ \\
\hline Dysphagia & $17(9.2)$ \\
\hline Dysgeusia & $15(8.1)$ \\
\hline Cough & $13(7.2)$ \\
\hline Foetor ex ore & $3(1.6)$ \\
\hline Throat pain & $2(1.1)$ \\
\hline Sneezing & $2(1.1)$ \\
\hline Others & $22(11.9)$ \\
\hline No clinical symptoms related to the respiratory tract & $95(51.4)$ \\
\hline Abnormalities of the oral cavity & $21(11.4)$ \\
\hline Activity of daily living (Barthel index) ${ }^{c}$ & $20(10-95)$ \\
\hline
\end{tabular}

aThe number of antibiotics is greater than 80 because some patients were treated with several antibiotics.

bThe number of symptoms is greater than 81 because some patients had several symptoms.

${ }^{\mathrm{c}}$ Median (range).

previous data and our findings point to a low colonization rate. Pneumococci were not found in any of the samples from the geriatric patients in this study. Since we were unable to isolate pneumococci in the pharynx of 185 geriatric hospitalized patients during the spring, pneumococcal colonization of the pharynx in elderly people may be much rarer than previously thought, and even multimorbid patients with age- and disease-related defects in their immune response such as those treated in our institution apparently are not colonized by $S$. pneumoniae.
Although our study population appears unique with respect to old age and the high degree of multimorbidity, our results were consistent with those of other studies: before vaccination, $S$. pneumoniae was isolated from the nose and throat swabs of only one out of 315 patients aged 60 years and older treated at a large tertiary referral hospital in Sydney. After immunization, none of the patients was carrying $S$. pneumoniae [7]. In 590 healthy Finnish people aged 65 years and older, the prevalence of nasopharyngeal carriage of encapsulated pneumococci was $1.5 \%$ [8]. 


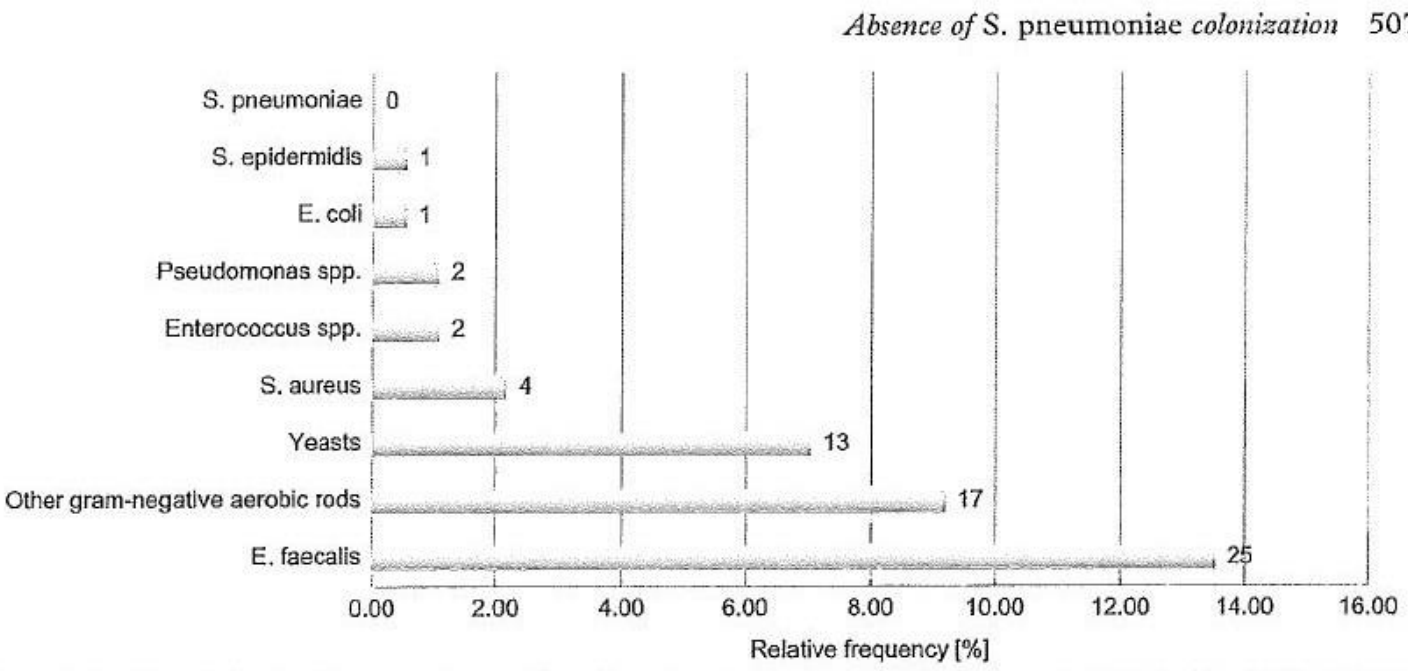

Figure 1. Relative and absolute frequency of potentially pathogenic bacteria grown from the pharyngeal swabs of 185 geriatric inpatients. In 168 patients, the cultures of pharyngeal swabs grew bacteria physiological to the oral cavity. Enterococcus faecalis and Other gram-negative aerobic rods were the most frequent potential pathogens. Streptococcus pneumoniae was not found in any of the cultures.

In Israel and Kenya, before routine vaccination, higher rates of nasopharyngeal carriage of $S$. pneumoniae were found in the community (Israel: $3.6 \%$ in $18-40$ year-olds, $3.8 \%$ in $41-65$-year-olds and $4.6 \%$ in $>65$-year-olds [9]; Kenya: $6.4 \%$ in 10-85-yearolds [10]). Conversely, in a study among Australian aborigines, in adults there was a trend towards increasing $S$. pneumoniae carriage with increasing age (17.3\% in 16-24-year-olds and $38.0 \%$ in $\geq 55$-year-olds) [11]. Very elderly people were apparently not investigated systematically in these studies.

In the present study, $S$. pneumoniae carriage was assessed by oropharyngeal culture to minimize discomfort to the patients. Nasopharyngeal swabs are considered to be the best sampling method for children. In adults, however, oropharyngeal cultures appear to be the more sensitive sampling method $[9,12]$. A delay in processing the samples of less than $4 \mathrm{~h}$ should not have influenced the results. For these reasons, we are confident that we did not underreport the number of patients colonized by $S$. pneumoniae. One reason why we did not find $S$. pneumoniae colonization at all may be the high rate of patients on antibiotics either during the study period or in the recent past (Table I), in conjunction with the low prevalence of penicillin-resistant pneumococci in Germany. In most studies in children, prior antibiotic use appeared to be associated with an increased rate of $S$. pneumoniae carriage $[13,14]$. Conversely, antibiotic treatment during or up to 1 month before screening probably lowers the $S$. pneumoniae carriage rate $[9,14,15]$. Seasonal variation probably was not responsible for our inability to detect $S$. pneumoniae colonization in elderly people: in a study in 1580 healthy Italian children aged 1-7 years, children carried slightly more $S$. pneumoniae in spring than in autumn [16]. In a Polish study, $S$. pneumoniae was isolated from $37 \%, 33.1 \%$ and $44.4 \%$ of the children in autumn, winter and spring; thus, again, colonization in spring was highest [14]. This was observed both in children attending day-care centers and in children staying at home. In 1-9-year-old children living in Virginia, USA, the rate of nasopharyngeal colonization by $S$. pneumoniae, Haemophilus influenzae and Moraxella catarrhalis was highest in winter, closely followed by spring, and considerably lower in summer and autumn [17]. To our knowledge, neither the effect. of antibiotic use nor the influence of the seasons on the pharyngeal colonization by $S$. pneumoniae has been studied in elderly people. The data obtained in children suggest that sampling in spring did not decrease the chance of isolating pneumococci from the pharynx of our patients, whereas the high rate of recent or persistent antibiotic treatment probably diminished S. pneumoniae colonization in our study. Recent data suggest that molecular methods, particularly polymerase chain reactions, are probably more sensitive in detecting low-density pneumococcal carriage than approaches relying on culture $[12,18,19]$. Since our primary goal was to isolate $S$. pneumoniae strains from geriatric patients for further investigations, we did not apply molecular methods.

In an experimental study, 29 out of 70 healthy adults receiving an intranasal challenge of S. pneumoniae type 6B were colonized. None of these subjects was colonized after experimental rechallenge, demonstrating the protective effect of the initial carriage against subsequent infection. Carriage increased both mucosal and serum immunoglobulin $G$ levels 


\section{N. Fomrich et al.}

to pneumococcal proteins and polysaccharides, and serum from colonized people conferred protection against a lethal $S$. pneumoniae challenge in a murine pneumonia model of invasive pneumococcal disease [20]. The authors concluded that mucosal pneumococcal vaccination strategies may be of value for vulnerable patient groups, particularly elderly people [10].

In spite of the low rate of colonization of adults observed in this and other studies, $S$. pneumoniae continues to be the most frequent pathogen found in community-acquired pneumonia: in a large German surveillance study of patients hospitalized for community-acquired pneumonia, the pathogen was isolated in $32 \%$, and in patients where the pathogen was identified, it was S. pnetumoniae in over $40 \%$ [3]. Of 3087 patients aged 65 years and older hospitalized for pneumonia acquired outside hospitals, 518 had nursing-home acquired pneumonia. When a pathogen was determined, $S$. pnetmoniae was the most frequent causative organism in both groups (community-acquired pneumonia, age $\geq 65$ years: $35.9 \%$; nursing-home acquired pneumonia: $32.5 \%$ ) [21].

In conclusion, the absence of pneumococcal carriage in this population of multimorbid hospitalized geriatric patients was unexpected. Together with previous hospital- and community-based studies in elderly people $[7,8]$, our observation suggests that long-term carriage of pneumococci is rare in elderly people, with the possible exception of some ethnic groups. Since pneumococcal carriage apparently conveys protection against subsequent infection [20], $S$. pneumoniae strains chronically colonizing the pharynx of elderly people are probably not the source of pneumococcal infections in this age group. Longterm carriage in geriatric patients appears to be very rare, and pneumococcal disease in this age group probably follows recent acquisition of $S$. pneumoniae types and is not associated with previous carriage.

Declaration of interest: The study was supported by the European Commission [CAREPNEUMO, grant agreement no. 223111]) and Sparkasse Göttingen. The authors declare that they have no commercial interests and no other conflicts of interests concerning this manuscript.

\section{References}

[1] Burman LA, Norrby R, Trollfors B. Invasive pneumococcal infections: incidence, predisposing factors, and prognosis. Rev Infect Dis 1985;7:133-42.

[2] Lee CI, Banks SD, Li JP. Virulence, immunity, and vaccine related to Streptococcus pneumoniac. Crit Rev Microbiol $1991 ; 18: 89-114$.

[3] Pletz MW, Rohde G, Schütte H, Bals R, von Baum H, Welte T, CAPNETZ-Studiengruppe. Epidemiologie und Erreger bei ambulant erworbener Pneumonie (CAP) Epidemiology and aetiology of community-acquired pneumonia (CAP)]. Dtsch Med Wochenschr 2011;136:775-80.

[4] Granger CV, Dewis IS, Peters NC, Sherwood CC, Barrett JE. Stroke rehabilitation: analysis of repeated Barthel index measures. Arch Phys Med Rehabil 1979;60:14-7.

[5] Bowen MK, Thiele LC, Stearman BD, Schaub IG. The Optochin sensitivity test: a reliable method for identification of pneumococci. J Lab Clin Med 1957;49:641-2.

[6] Zysk G, Brück W, Gerber J, Brück Y, Prange HW, Nau R. Anti-inflammatory treatment influences neuronal apoptotic cell death in the dentate gyrus in experimental pneumococcal meningitis. J Neuropathol Exp Neurol 1996; 55:722-8.

[7] Ridda I, Macintyre CR, Lindley R, McIntyre PB, Brown M, Oftadeh S, et al. Lack of pneumococcal carriage in the hospitalised elderly. Vaccine 2010;28:3902-4.

[8] Palmu AA, Kaijalainen $T$, Saukkoriipi A, Leinonen $M$, Kilpi TM. Nasopharyngeal carriage of Streptococcus pneumoniae and pneumococcal urine antigen test in healchy elderly subjects. Scand J Infect Dis 2012;44:433-8.

[9] Regev-Yochay G, Raz M, Dagan R, Porat N, Shainberg B, Pinco E, et al. Nasopharyngeal carriage of Streptococcus pneumoniae by adults and children in community and family settings. Clin Infect Dis 2004;38:632-9.

[10] Abdullahi O, Nyiro J, Lewa P, Slack M, Scott JA. The descriptive epidemiology of Streptococcus pneumoniae and Haemophilus influenzae nasopharyngeal carriage in children and adults in Kilifi district, Kenya. Pediatr Infect Dis J $2008 ; 27: 59-64$

[11] Mackenzie GA, Leach AJ, Carapetis JR, Fisher J, Morris PS. Epidemiology of nasopharyngeal carriage of respiratory bacterial pathogens in children and adults: cross-sectional surveys in a population with high rates of pneumococcal disease. BMC Infect Dis 2010;10:304.

[12] Trzcinski K, Bogaert D, Wyllie A, Chu MLJN, van der Ende A, Bruin JP, et al. Superiority of trans-oral over trans-nasal sampling in detecting Streptococcus pneumoniae colonization in adults. PLoS One 2013;8:e60520.

[13] Katsarolis I, Poulakou G, Analitis A, Matthaiopoulou I, Roilides E, Antachopoulos C, et al. Risk factors for nasopharyngeal carriage of drug-resistant Streptococcus pneumoniae: data from a nation-wide surveillance study in Greece. BMC Infect Dis 2009;9:120.

[14] Korona-Glowniak I, Malm A. Characteristics of Streptococcus pneumoniae strains colonizing upper respiratory tract of healthy preschool children in Poland. ScientificWorldJournal 2012;2012:732901

[15] Pebody RG, Morgan O, Choi $Y$, George R, Hussain M, Andrews N. Use of antibiotics and risk factors for carriage of Streptococcus pneumoniae: a longitudinal household study in the United Kingdom. Epidemiol Infect 2009;137:555-61.

[16] Marchisio P, Gironi S, Esposito S, Schito GC, Mannelli S, Principi N; Ascanius Project Collaborative Group. Seasonal variations in nasopharyngeal carriage of respiratory pathogens in healthy Italian children attending day-care centres or schools. J Med Microbiol 2001;50:1095-9.

[17] Hendley JO, Hayden $F G$, Winther $B$. Weekly point prevalence of Streptococcus pneumoniae, Hemophilus influenzae and Moraxella catarrhalis in the upper airways of normal young children: effect of respiratory illness and season. APMIS 2005;113:213-20.

[18] da Gloria Carvalho M, Pimenta FC, Jackson D, Roundtrec A, Ahmad Y, Millar EV, et al. Revisiting pneumococcal carriage by use of broth enrichment and PCR techniques for enhanced detection of carriage and serotypes. J Clin Microbiol 2010;48:1611-8. 
Absence of S. pneumoniae colonization 509

[19] Cvitkovic Spik V, Beovic B, Pokorn M, Drole Torkar A, Vidmar D, Papst L, et al. Improvement of pneumococcal pneumonia diagnostics by the use of RT-PCR on plasma and respiratory samples. Scand J Infect Dis 2013; 45:731-7.

[20] Ferreira DM, Neill DR, Bangert $M$, Gritzfeld JF, Green $N$, Wright AKA, ex al. Controlled human infection and

\section{Supplementary material available online}

Supplementary Appendix. Questionnaire rechallenge with Streptococcus pneumoniae reveals the protective efficacy of carriage in healthy adults. Am J Respir Crit Care Med 2013;187:855-64.

[21] Ewig S, Klapdor B, Pletz MW, Rohde G, Schütte $H$ Schaberg T, et al.; CAPNETZ study group. Nursing-homeacquired pneumonia in Germany: an 8-year prospective multicentre study. Thorax 2012;67:132-8. 


\section{Danksagung}

Herrn Prof. Dr. Nau danke ich ganz herzlich für die Bereitstellung des Themas, die Möglichkeit in seiner Klinik die Studie durchzuführen und die sehr freundliche und unterstützende Betreuung. Einen besonderen Dank möchte ich auch für die Möglichkeit der Veröffentlichung der Daten aussprechen.

Zudem möchte ich mich sehr bei Prof. Dr. Dr. Helmut Eiffert für die gute Zusammenarbeit in seinem Labor bedanken. Besonders Danken möchte ich auch Frau Kellner, die mich bei den Laborarbeiten so tatkräftig unterstützt hat. 